T. Kolb, M. Aigner, R. Kneer, M. Müller, R. Weber, N. Djordjevic, Tackling the challenges in modelling entrained-flow gasification of low-grade feedstock, J. Energy Inst. 89 (2016) 485-503

The original publication is available at www.elsevier.com

http://dx.doi.org/10.1016/j.joei.2015.07.007 


\title{
Tackling the challenges in modelling entrained-flow gasification of low- grade feedstock
}

\author{
Thomas Kolb ${ }^{1,6}$, Manfred Aigner ${ }^{2}$, Reinhold Kneer ${ }^{3}$, Michael Müller ${ }^{4}$, Roman Weber ${ }^{5}$, Neda \\ Djordjevic $^{6}$ \\ ${ }^{1}$ EBI-ceb, KIT, Germany, ${ }^{2} V T$, DLR Stuttgart, Germany, ${ }^{3}$ WSA, RWTH Aachen, Germany, ${ }^{4} I E K-2$, \\ FZJ, Germany, ${ }^{5}$ IEVB, TU Clausthal, Germany, ${ }^{6}$ ITC, KIT, Germany
}

\begin{abstract}
Development of a new technology for conversion of residual biomass into a liquid fuel via pyrolysis - gasification - gas cleaning - synthesis is the overall objective of the on-going bioliq ${ }^{\circledR}$ project. The present paper gives an overview on research activities dedicated to mathematical modeling of entrained-flow gasification for conversion of biomass-based suspension fuels into a medium calorific (LCV around $15 \mathrm{MJ} / \mathrm{kg}$ ) synthesis gas. The objective is to identify knowledge gaps that currently prohibit a knowledge-based mathematical description of reacting high-pressure multiphase flows so as to model the bioliq ${ }^{\circledR}$ gasification reactor in particular and biomass conversion in entrained flow gasifiers in general. Substantial knowledge gaps for high pressure process conditions have been identified for atomization of high viscous liquids, gasification chemistry for biomass-based fuels, radiative heat transfer as well as slag formation mechanisms. The paper proposes an interdisciplinary research approach in a holistic manner to close these gaps.
\end{abstract}

Key words: high pressure entrained-flow gasification, suspension fuel, biomass, numerical simulation, bioliq $^{\circledR}$ process

\section{INTRODUCTION}

Low-grade energy resources (e.g. low rank coals, biomass, waste derived fuels, tar sands, oil shale) feature high heterogeneity, low calorific values and a high content of inert material. For utilization in efficient energy conversion processes, these energy resources have to be converted to high quality, process adapted, chemical energy carriers. The conversion of low-grade fossil and biogenic energy resources to syngas in a high-pressure entrained-flow gasification process opens a wide spectrum of applications for utilization of these low-grade feedstocks as both carbon and energy source. The produced syngas can be converted to basic chemicals (e.g. methanol, DME - dimethyl ether - $\mathrm{CH}_{3} \mathrm{OCH}_{3}$ ), gaseous fuels (Synthetic Natural Gas - SNG), liquid fuels (gasoline, diesel) or it can be fired in a gas turbine of an integrated gasification combined cycle power plant (IGCC) to generate electricity and heat. The combination of chemical synthesis and IGCC, the so called polygeneration, provides maximum fuel- and product-flexibility at high overall energy conversion efficiencies. Since entrained-flow gasifiers operate at high pressure and produce a tar-free syngas, the produced syngas can be fed to subsequent process steps without further compression and measures to clean up the gas can be minimized.

Entrained-flow gasification is the most widely employed gasification technology worldwide due to its advantage to produce a tar-free syngas at high pressure from a wide range of solid and liquid feedstocks [1]. The design and optimization of the technical systems is based on practical experience and coarse simulation tools. The reactor design and the process optimization for more complex lowgrade fuels such as e.g. biomass-based chars, oils and suspension fuels (slurries) is very challenging due to the lack of in detail understanding of the different process steps governing such reacting highpressure multiphase systems.

Development of a new technology for conversion of residual biomass with low energy density into a liquid fuel via pyrolysis - gasification - gas cleaning - synthesis is the overall objective of the ongoing bioliq $q^{\circledR}$ project $[2,3]$. The present paper gives an overview on research activities under the umbrella of the Helmholtz Virtual Institute for Gasification Technology (HVIGasTech), dedicated to mathematical modeling of entrained-flow gasification as a process step for conversion of biomass 
based suspension fuels into a synthesis gas $[4,5]$. The bioliq ${ }^{\circledR}$ project contributes to the German energy transition process (Energiewende) [6]. The bioliq ${ }^{\circledR}$ high pressure entrained flow gasifier is operated at $5 \mathrm{MW}_{\text {thermal }}$ input and at a nominal pressure of 40 to 80 bar. Operation of the pilot scale process chain generates data for process optimization, scale-up and design of an industrial size unit. Simulation tools have proven to accelerate technology development and they play a key role in minimizing risks associated with scale-up. The objective of this paper is to identify knowledge gaps that currently prohibit a knowledge-based mathematical description of reacting high-pressure multiphase flows so as to model the bioliq ${ }^{\circledR}$ reactor in particular and fuel conversion in entrained-flow gasifiers in general. Such a task has been currently undertaken $[7,8]$ and action has been taken to close the gaps, as described below. It is then self-evident that numerous technical questions are going to be formulated in this paper and many will remain unanswered awaiting clarification through appropriate research.

The entrained-flow gasifiers considered in this paper are being fed either with glycol or a slurry made out of glycol and bio-char (REGA- gasifier; see below) or with a bio-slurry (bioliq ${ }^{\circledR}$ gasifier) produced in a fast pyrolysis process. The pyrolysis process delivers bio-oil and char (named in this paper as primary char) which are then mixed to produce a bio-slurry of a density around $1,200 \mathrm{~kg} / \mathrm{m}^{3}$ and LCV in the 16-22 MJ/kg range. A droplet of this slurry is then a droplet of the bio-oil which contains micron-size particles of the primary char. Details of the pyrolysis process and description of the slurry properties can be found elsewhere [9].

\section{SCIENTIFIC CHALLENGES}

In high-pressure entrained flow gasifiers the low-grade feedstock can be fed as pulverized solid fuel, as liquid, or liquid containing solid material (suspension fuel, slurry). The bioliq ${ }^{\circledR}$ oxygen-blown entrained flow gasifier is designed to operate at temperatures in excess of $1200{ }^{\circ} \mathrm{C}(1473 \mathrm{~K})$ and pressures as high as 40 and 80 bar. The major scientific challenge is the mathematical modelling (and its experimental validation) of such a high-pressure reacting system consisting of gaseous, liquid and solid phases. In order to illustrate the sub-processes occurring in the entrained flow gasifier, Fig. 1 shows the discrete phase trajectories obtained using simplified numerical simulations of a slurry-fed gasifier (see Fig. 13 in Ref [8]). Colours represent the different characteristic thermo-chemical processes for slurry gasification:

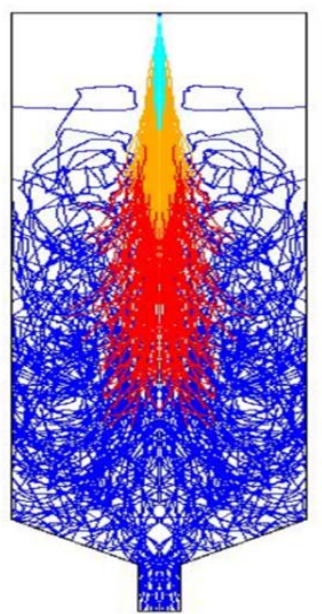

Figure 1: Trajectories of the slurry droplets in an entrained flow gasifier [8] (a) Atomization of the high viscous suspension to generate fine droplets containing one or more solid (primary char) particles. In the numerical simulations shown in Fig. 1, as a simplified approximation, each slurry droplet is considered to be formed by a solid core enveloped by a liquid droplet. The atomization process was not simulated, but instead the droplet size distribution was determined in the isothermal spray characterization experiments and introduced as inlet boundary condition into the simulation.

(b) Evaporation (light blue) of the liquid components surrounding the solid core.

(c) Heating-up and Pyrolysis (orange) of the primary char particles. This sub-process is relatively fast and requires only milliseconds to complete. The process results in a solid particle denoted as secondary char, featuring different morphology and reactivity as compared to the original (primary char) solid particle of the feed flow. The secondary char may also contain solids generated from thermal degradation of the liquid phase.

(d) Gasification (red) e.g. heterogeneous reactions of the secondary char with steam and carbon dioxide which may proceed in parallel with oxidation reactions 
(e) Slag pathway (dark blue) e.g. trajectories of the ash particles and their impact on the wall. At high temperatures, volatile ash components (e.g. sodium and potassium components) may evaporate and may be present in the gas-phase [10].

During each of the above underlined process steps, gaseous components are released from the slurry droplet and char particle forming a gas mixture of spatially varying composition. Fig. 2 schematically illustrates the coupling of heterogeneous and homogeneous thermo-chemical processes during gasification of a slurry droplet. As the heterogeneous conversion processes are generally slower, as compared to the homogeneous reactions, they are the rate determining steps. However, the homogeneous reactions determine the local temperature field which has an essential influence on the conversion rate of the solids (secondary char). The evaporated liquid phase components, the volatile matter of the solid-phase, as well as the gaseous products of thermal degradation react with oxygen in exothermic reactions leading to high local temperatures. As the amount of oxygen in the system is limited, the oxygen is mainly consumed by homogeneous reactions; the secondary chars react with $\mathrm{CO}_{2}$ and $\mathrm{H}_{2} \mathrm{O}$ in endothermic reactions leading to a decrease of local temperatures.

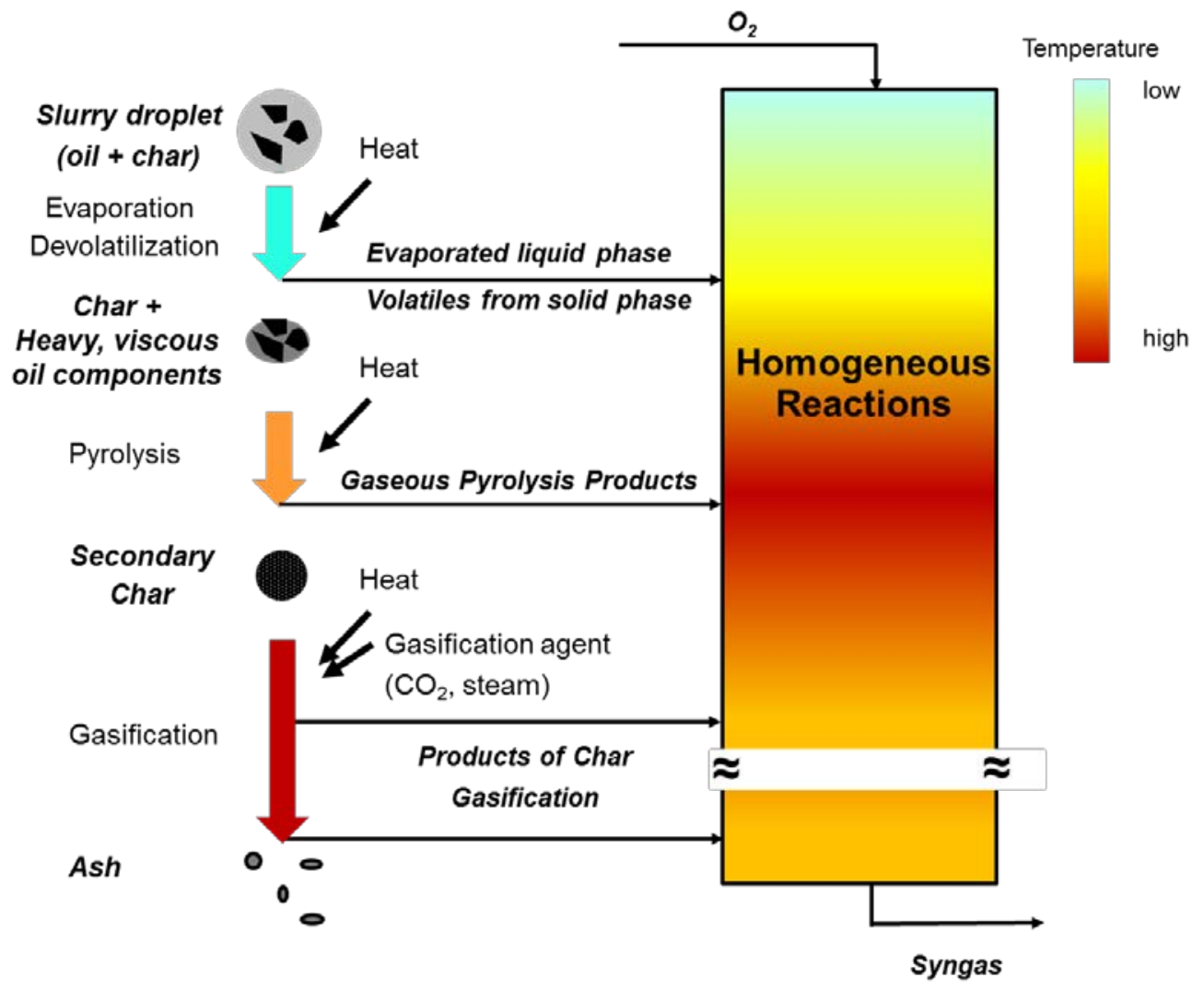

Figure 2: Schematic representation of thermo-chemical sub-processes during entrained flow gasification of a slurry droplet

Based on the general description provided above, technical and scientific key challenges associated with mathematical description of oxygen-blown entrained-flow gasification can be identified. In the following, major scientific issues connected with such challenges are discussed.

\subsection{Slurry feed / Atomization}

Efficient operation of an entrained-flow gasifier requires complete fuel conversion into a tar-free syngas at minimum oxygen consumption in order to maximize cold gas efficiency (CGE). To reach this goal, the slurry has to be distributed in a fine spray by the burner nozzle, as the droplet size distribution has a significant influence on fuel conversion and syngas quality [8]. Steam and oxygen are used as gasification media. These media are also utilized as atomization agent in twin-fluid nozzles. Since gasification reactions are to proceed at a pre-defined (low) stoichiometry, the amount of oxygen-steam available for atomization is limited and the atomizers are to operate at a low gas-to- 
liquid ratio (GLR). For biogenic feedstock the steam flow has to be minimized, due to the high oxygen content of the biomass-based fuel.

Slurry, consisting of biogenic char suspended in pyrolysis oil condensate (Fig. 3), features viscosities of up to 1 Pas. Properties of such a slurry change with time unless strict measures are taken to prohibit sedimentation. Therefore handling of biogenic slurries is challenging. Atomization of such slurries must be performed at low velocity of the suspension in order to avoid abrasion in the atomizer nozzle which may occur due to the solid particles presence. The energy necessary for spray generation is then provided by the oxygen stream entering a twin-fluid atomizer. An additional challenge is the non-Newtonian behavior of suspensions resulting in variation of viscosity with the shear rate the suspension is subjected to during mixing, pumping and atomization.

In literature numerous studies concerning twin-fluid atomization of low viscous liquids at atmospheric pressure conditions are found e.g. using lab-scale spray-rigs [11] as well as full industrial-size sprays (300 kg/h oil flow rate) [12,13]. Generally, detailed investigations using state-of-the-art advanced measuring techniques reported on twin-fluid atomization at elevated pressures are scarce. Investigations on the influence of ambient pressure on atomization of low-viscous liquids have been performed [1416]. Different semi-empirical correlations for Sauter Mean Diameter (SMD) describing the droplet size distribution in the spray have been suggested. Nevertheless, the reported influence of the operational parameters on SMD from these correlations is sometimes inconsistent and in some cases even contradictory. The studies attempting to quantify the influence of non-Newtonian rheological behavior of liquids and suspensions on atomization process are rather rare [17-20], especially at high reactor pressure. Therefore, there is a need for comprehensive

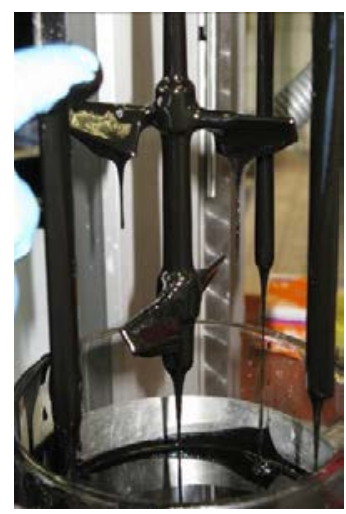

Figure 3: Biogenic slurry $(30 \%$ char in pyrolysis oil) systematic investigations on the influence of operational parameters, especially pressure, and also of fluid rheology on twin-fluid atomization using advanced state-of-the art measuring techniques. Such experimental data on local spray quality are necessary as input data for CFD modeling of entrained flow gasification.

\subsection{Particle / droplet conversion}

The solid particles fed to the gasifier or liquid/slurry droplets released from the atomizer are converted through several thermo-chemical sub-processes (Fig. 2). When solid particles or slurry droplets are introduced into high temperature gas flow they are subjected to heating rates as high as $10^{4}-10^{5} \mathrm{~K} / \mathrm{s}$. The heating rate has an essential influence on the pyrolysis process affecting both, the composition of the volatiles and the morphology of the secondary char [21]. Thus, structure and reactivity of the secondary char actually involved in gasification reactions depend on heating rates and reactor temperatures. Subsequent heterogeneous conversion of this secondary char involves several sub-process steps, which may be more or less conversion rate determining, depending on reactor temperature and pressure as well as physical structure and chemical composition of the fuel [22].

Apparent reaction rates of the char depend on transport of gaseous reactants from the gas-phase to the outer particle surface, on the intra-particle diffusion and on the chemical reaction rate at the char surface. At low temperatures the chemical reaction at the char inner and outer surface is the rate determining step (regime I). At higher temperatures pore diffusion within the char particles is limiting the conversion rate (regime II) [22-25]. At even higher temperatures the reaction rate is limited by mass transfer within the boundary layer surrounding the particle (regime III). The transition temperatures between these three regimes depend on properties of the solid particle, such as pore structure and reactivity. According to Roberts and Harris [26], expected transition temperatures between regime II and III are $>2000 \mathrm{~K}$ for $\mathrm{CO}_{2}$ and $\mathrm{H}_{2} \mathrm{O}$ gasification. This means that entrained-flow gasification of biomass chars takes place under regime I or regime II conditions. To describe the conversion process in these regimes, fuel data for chemical controlled conversion as well as information about physical structure and pore diffusion is mandatory. 
Kinetic data for the conversion process of solid fuel particles in a gasification atmosphere, e.g. reactions of chars merely with $\mathrm{CO}_{2}$ and $\mathrm{H}_{2} \mathrm{O}$, are available in literature for a number of coals, but the data for biomass chars are limited [27]. Such data are mainly derived from thermo-gravimetric analysis (TGA) at low heating rates $(<1 \mathrm{~K} / \mathrm{s})$ and ambient pressure [28], whereas the data at elevated pressures are rather scarce. A tubular reactor was employed to observe the kinetic behavior of coal chars during gasification in a pressurized $\mathrm{CO}_{2}$ atmosphere in [29]. Besides the intrinsic rates of combustion and gasification reactions, which are influenced by the partial pressure of the reactants, the reactor (total) pressure significantly influences the devolatilization and therewith the morphology of the char produced [30, 31]. Thus, it is essential to extend the existing data-bases for biomass based fuels, by generating data concerning the pressure influence on gasification rates at elevated pressure.

\subsection{Slag}

To deal with the high ash content of low-grade fuels, an entrained flow gasifier for these fuels is typically equipped with a cooling screen. By maintaining the process temperature optimized to the slag melt properties of the specific fuel, a firmly adhering slag coat is applied to the refractory liner, protecting the material from chemical and thermal wear and the reactor from corrosion. Thus, the molten slag flows downwards along the reactor walls and is discharged as solid material into a water quench. In order to control the slag flow along the cooling screen and out of the reactor, the knowledge of chemical and physical properties of gasifier slags as a function of slag and gas-phase composition, temperature and pressure is necessary.

Measurements on complex and reactive systems such as gasifier slags at high temperature are challenging and often not feasible for the range of composition, temperature, and pressure of technological interest. Computer based thermo-chemistry permits generation of results within a shorter time and at low costs while allowing variation of parameters such as temperature, pressure, and chemical composition of the system. Moreover, the thermodynamic properties shall only be calculated in the temperature, pressure and composition ranges of the experimental data on which the data assessment has been based, but extrapolations into extended regions are required. Current investigations have shown that the commercially available databases are not sufficient to model the complete slag and gas system of a biomass fed gasifier [32-34]. Therefore, a new database is necessary, optimized for slags from low-grade biogenic and fossil feedstock.

Substantial efforts have been made to develop models for predicting viscosity of melts [35]. Temperature dependence of viscosity has been extensively investigated and numerous temperaturerelated models have been developed among them the Arrhenius model being perhaps the most popular one. As the investigation of the temperature dependence itself is not sufficient, the effect of composition on viscosity is coupled to the viscosity models. Common models for silicate melts are for example the models of Shaw [36] and Urbain [37]. Since these models are semi-empirical and lack the sufficient consideration of the melt's structure, they are only valid in their own compositional range. New attempts to calculate rheological properties of melts on basis of a thermodynamic description of the melt's structure are under development $[38,39]$ and their suitability for complex fuel slags has to be proven.

\subsection{Heat transfer}

The reactor temperatures, affecting both fuel conversion rates (see Section 2.2) and slag flow (see Section 2.3), are determined by the rate of gas-phase chemical reactions proceeding in turbulent flow and by heat transfer. In high-pressure entrained-flow gasification, radiation is the dominant heat transfer mode due to both high temperatures and high pressures. Typically, the convective heat transfer amounts to not more than $10-20 \%$ of the overall heat transfer rate. Although carbon dioxide and water vapour remain the most important radiative gases, carbon monoxide's contribution should also be taken into account. Moreover, (blackbody) radiation coming from the solid particles in the entrained flow gasifier, contributes to the total heat transfer rate. 
There exist numerous methods for the calculation of spectral emissivities (or absorptivities) at atmospheric pressure and the most accurate ones are based on line-by-line calculations which utilize spectral data-bases such as HITEMP [40] or CDSD-1000 [41]. The RADCAL narrow-band model of Grosshandler [42] or the exponential-wide-band model of Edwards and Balakrishnan [43-45] are also in use. However, there are hardly any radiative property models available [46] which allow for calculating absorption coefficients and/or emissivities of $\mathrm{CO}_{2} / \mathrm{H}_{2} \mathrm{O} / \mathrm{CO} / \mathrm{H}_{2}$ mixtures at pressures as high as 40-80 bar. Typically, Hottel's emissivity graphs [47] or Leckner's [48, 49] correlations are used to estimate emissivities of gaseous mixtures containing carbon dioxide, carbon monoxide and water vapour. However, their usage requires extrapolations of unknown accuracy. Furthermore, absorption and scattering by droplets and solid particles has to be considered. This knowledge (model) gap must be closed if CFD-based mathematical models of high-pressure gasification processes were to become reliable.

\subsection{Numerical simulations of entrained-flow gasification}

Gasification in turbulent flows is multi-physics and multi-scale by nature which makes the numerical approach challenging. When the appropriate numerical algorithms are implemented highly non-linear processes can be coupled and tracked in time and space. Because of its computational efficiency and its adequate accuracy, the Reynolds-Averaged Navier-Strokes (RANS) method is used for time-averaging. The backbone for the numerical simulation is a CFD code which accurately captures details, from the fluid-flow through the gas inlet and the slurry injection system, and carries them over downstream where less geometrical complexities are encountered (see for example Ref. [50, 51]). The task to create an efficient and comprehensive, RANS-based design tool for performance predictions of entrained-flow gasifiers requires input and development in several aspects:

- A skeletal gas-phase reaction mechanism for gasification conditions must be developed and implemented, specifically for non-conventional fuels

- The liquid/solid fuel and its mass and energy exchange with the gas-phase has to be modelled using either Lagrangian or Eulerian approach. A model/method for determination of droplets/particles diameter distribution and input velocities (see Section 2.1) is required.

- A model for solid particles conversion (see Section 2.2) through heterogeneous reactions with $\mathrm{CO}_{2}$ and $\mathrm{H}_{2} \mathrm{O}$ has to be implemented.

- Particles impacting on the walls will eventually be trapped in the slag. Equations for the movement of molten slag along the walls have to be incorporated into the CFD code. The heat transfer through the slag layer has to be accounted in order to determine in which phase (molten or solid) the slag remains. The slag viscosity, its composition and melt fraction are to be calculated using the new database to be developed (see Section 2.3). In other words, a slag sub-model is required.

- In order to model reliably the heat transfer, new radiative property correlations (absorption and scattering coefficients), as described in Section 2.4, must be incorporated into the solution of the radiative heat transfer equation (RTE).

While RANS methods might be sufficient as predictive tools for design of the downstream section, more detailed methods, like the Large Eddy Simulations (LES) approach, have to be used to develop sub-models of selected physical processes, such as:

- atomization

- vaporization of emulsions and suspensions

- impingement of slag particles on the walls

- turbulent dispersion of particles (liquid and solid).

\subsection{Experimental data for model development and validation}

Experimental data concerning operation of pilot-scale entrained flow gasifiers are essential for understanding of the process and for model development and validation. Due to both, the harsh conditions inside gasifiers (high pressure, high temperature, particles, and slag) and restricted accessibility for in-vessel measurements, the existing measurements are limited to determination of 
input-output parameters (educts and products) of the process [52-57]. There are several research groups operating entrained-flow reactors in a bench-scale [58-60]. At the University of Utah semipilot, an oxygen-blown pressurized entrained flow gasifier ( $30 \mathrm{bar}, 1600^{\circ} \mathrm{C}, 500 \mathrm{~kW}, 1.5 \mathrm{ton} /$ day) featuring good optical accessibility is available [61]. TU Bergakademie Freiberg operates a 5 MW(th) high pressure POX plant for syngas generation from gaseous and liquid hydro carbons at a typical fuel input of $500 \mathrm{~kg} / \mathrm{h}$ [62]. The test facility of SIEMENS Fuel Gasification Technology GmbH \& Co. KG includes an entrained flow gasification reactor with an output of 3-5 MW(th) at 30 bar, complemented by various conveying and feeding systems $(300 \mathrm{~kg} / \mathrm{h})$ [63]. Entrained flow gasification of Black Liquor has been also investigated on a 3 MW, 30 bar pilot-scale facility [64].

In the context of our work, the REGA gasifier [8] and the bioliq ${ }^{\circledR}$ pilot-scale gasifier $[2,3]$ are used to generate experimental data for the development of mathematical sub-models and for evaluation of process simulation tools. The REGA experimental gasifier, operated at atmospheric pressure with a fuel flow rate of $10-15 \mathrm{~kg} / \mathrm{h}$, allows not only for input-output measurements but also for in-vessel measurements using both intrusive probes and non-intrusive laser based techniques (see Section 3.5). Thus, experiments are conducted using a wide spectrum of low-grade fuels at various operating conditions (stoichiometry, temperature, residence time) with detailed in-vessel mapping of the temperature and the species distribution. The bioliq ${ }^{\circledR}$ pilot scale facility allows for collecting data at gasification conditions of 40-80 bar pressure. Gas and solids samples are collected from the raw gas leaving the gasification process to evaluate the overall performance of the process as function of fuel specification and operational parameters (e.g. stoichiometry, atomization, pressure). Furthermore, an optical access to the reaction zone in this complex, pressurized, slagging system is provided for measurement of local temperature and species distribution. A possibility to derive local energy balances in order to estimate local heat flux to the cooling screen using experimental data exists and provides an excellent basis for model validation.

Optical and laser-based measurement techniques are used regularly to investigate reacting (combusting) flows. A wide range of different techniques exist to measure a variety of different quantities like velocity, temperature, species concentrations, or particle density in a non-intrusive way. They deliver in-flame or in-vessel data and are valuable in both enhancing the understanding of the process and in producing data for validation of numerical simulations. Some of these measurement techniques can be used for online monitoring to deliver parameters for process control and optimization. Because of the harsh conditions inside a pressurized gasifier, adaptation of these measurement techniques is not straight forward. The first challenge is in providing an optical access so as to guarantee a signal of sufficiently high signal-to-noise-ratio. In short, application of these techniques to high pressure gasification requires further development and testing. Several measurement techniques have proven their usability in harsh combustion environments [65-68]. For example, emission spectroscopy e.g.. the spectrally resolved detection of the radiation emitted by the flame, yields information about chemiluminescent species, locations of heat release and possibly temperature and local stoichiometry. Absorption spectroscopy delivers information about the concentrations of molecular species and particle density. Laser-induced incandescence (LII) enables 2D measurements of soot volume fraction [69]. Laser-induced breakdown spectroscopy (LIBS) yields the local atomic composition within a probe volume, from which information of the local mixture fraction and of the concentration of other species can be obtained [70]. In context of the present research concept, applicability of these measurement techniques to gasification processes is going to be tested using both REGA and bioliq ${ }^{\circledR}$ gasifiers.

\section{TACKLING THE CHALLENGES: SCIENTIFIC APPROACH}

As it has been pointed out in the introduction, the objective of the research work conducted under the scope of the Helmholtz Virtual Institute for Gasification Technology - HVIGasTech [7] is to derive and evaluate a numerical simulation tool for design and scale-up of industrial-scale high pressure entrained flow gasifiers. The integrated multi-scale, cross-disciplinary research approach addresses afore described challenges. It comprises three strongly cross-linked tasks, as shown in Fig. 4:

Data evaluation to generate input data for numerical simulation, 
Detailed simulation of sub-processes and the overall gasification process and

Validation based on experimental data collected at different scales.

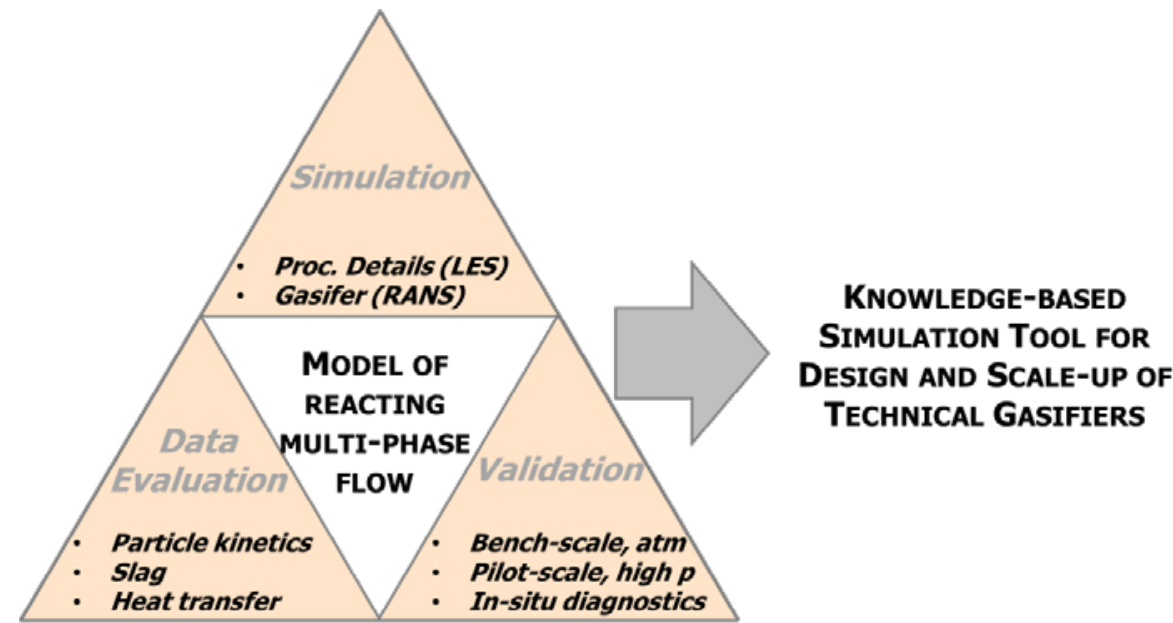

Figure 4: The research concept of Helmholtz Virtual Institute for Gasification Technology (HVIGasTech)

\subsection{Twin-fluid atomization}

The present work focuses on establishing the influence of liquid properties (dynamic viscosity, Newtonian / non-Newtonian rheological behavior) and operational parameters (pressure, gas-to-liquid ratio, injection velocities) on sprays generated by twin-fluid atomization. The work has been carried out at the Atmospheric Spray Test Rig (ATMO) [8] employing the line-of-sight laser diffraction drop size detector. Visualizations of the near nozzle jet disintegration have been captured by a high-speed camera. To investigate the influence of fluid rheology on the atomization process, different liquids with increasing rheological complexity are used. Glycerol of $99.5 \mathrm{wt} . \%$ purity $\left(\eta=1484 \mathrm{mPas}\right.$ at $20^{\circ} \mathrm{C}$ / 293K) has been diluted with pure water to obtain various Newtonian liquids with different dynamic viscosities in the range of $1 \mathrm{mPas}$ (water) up to $160 \mathrm{mPas}$. Non-Newtonian liquids are being prepared by adding various amount of carboxymethylcellulose (CMC) to pure water. In order to observe the effect of shear thinning, the zero viscosity $\eta_{0}=\eta(\dot{\gamma} \rightarrow 0)$ of the non-Newtonian CMC/water solutions has been adjusted to the dynamic viscosity of the Newtonian glycerol/water solutions (50, 100 and 160 mPas).

The results are shown in Fig. 5. Generally, an increase of gas-to-liquid ratio (GLR) leads to a decrease of SMD for all fluids investigated. For high GLRs, corresponding to high aerodynamic forces, the effect of fluid rheology is minor. Nevertheless, for the entrained flow gasifier a GLR $<1$ range is relevant, as the amount of atomizing agent is limited by the process stoichiometry. In this GLR range the influence of fluid rheology is significant. Generally, an increase in dynamic viscosity leads to an increase in SMD. The shear-thinning liquids exhibit lower SMD values than the corresponding Newtonian liquids with the same zero dynamic viscosity. This is due to the lower actual viscosity at the high shear rates present at the nozzle exit. 


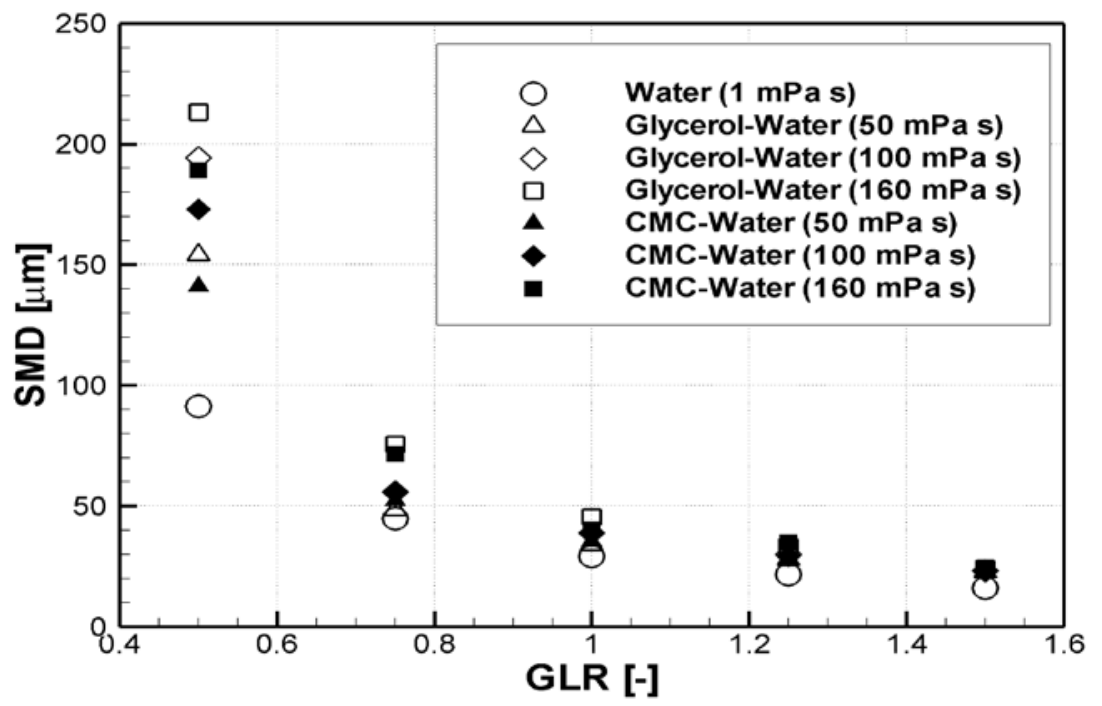

Figure 5: Influence of fluid rheology on spray quality - SMD at $100 \mathrm{~mm}$ downstream from the atomizer for various gas-to-liquid ratio (GLR)

In Fig. 6 the influence of different dynamic viscosities and rheological behavior on the primary jet breakup is illustrated. Whereas the breakup into droplets takes place in the near nozzle region for water (left), the increased dynamic viscosity of the glycerol/water mixture (middle) damps the jet disintegration. It can be seen that large liquid ligaments remain intact in the near nozzle region and then disintegrate into droplets further downstream as compared to the water spray. The visualization of jet breakup of the CMC/water - mixture shows more droplets and fewer ligaments. This is due to the shear-thinning behavior resulting in lower actual viscosity at the nozzle orifice. Such shear-thinning rheological behavior is characteristic for suspension fuels.

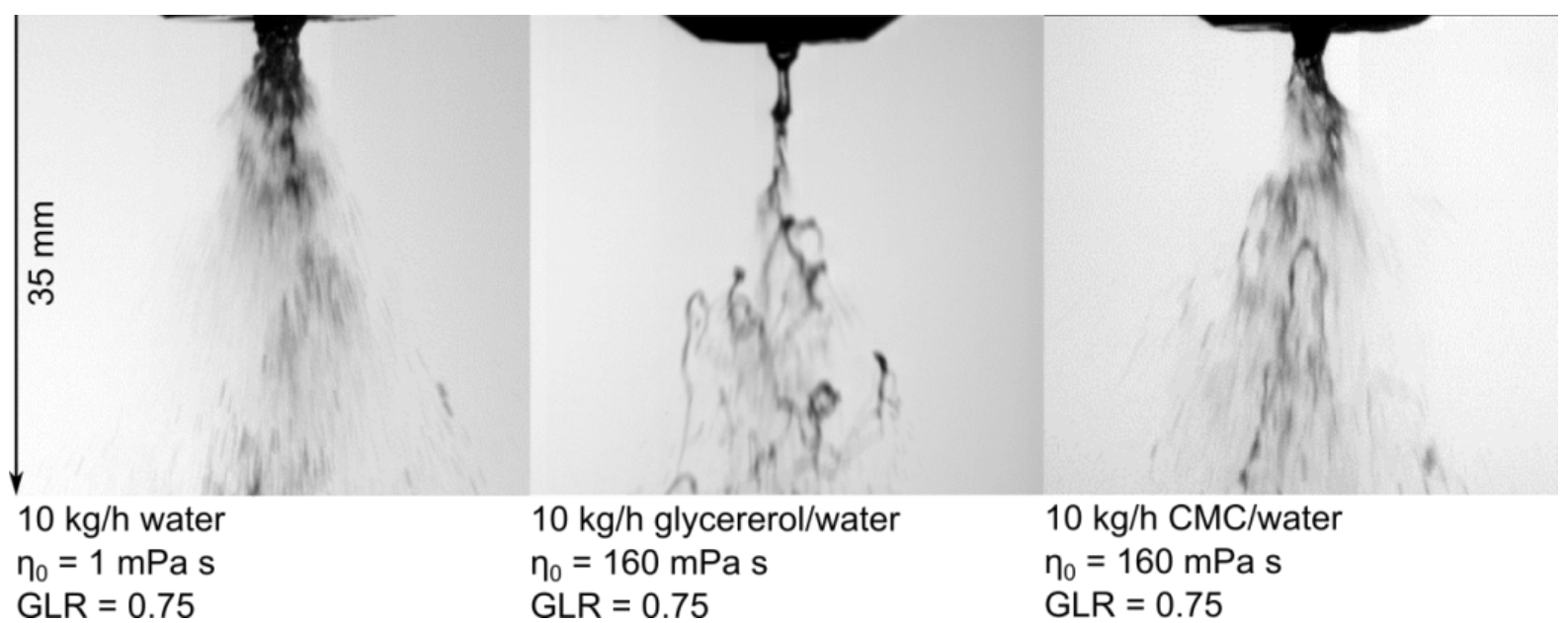

Figure 6: High-speed visualizations of the atomization process for fluids of different rheological complexity

Atomization at elevated pressures has been investigated using the Pressurized Atomization Test Rig (PAT) [71]. To measure droplet size distribution and axial droplet velocity a 2D-fibre PhaseDoppler-Anemometer (PDA) is used. The influence of reactor pressure on atomization of low viscous fluids (water) has been investigated by recording the local spray data for varying process parameters. In twin-fluid atomization the Weber number $W e=\left(\rho_{\text {air }} \cdot u_{\text {relative }}^{2} \cdot d_{\text {jet }}\right) / \sigma$ is used to correlate the Sauter Mean Diameter (SMD) with atomization fluid dynamics [11]. Therefore, the experiments are conducted at various reactor pressures, which are varied in a $2-21$ bar range, while keeping the Weber number at a constant value. 
Radial profiles of SMD and mean axial droplet velocity measured at $200 \mathrm{~mm}$ distance downstream of the nozzle are shown in Fig. 7. The data have been taken at 2 and 21 bar absolute pressure while keeping the Weber number constant at $\mathrm{We}=500$. A typical radial profile of the measured SMD, with a minimum located on the spray axis, as reported in the literature [72], can be observed in Fig. 7 for the 2 bar spray. At 21 bar pressure a quite uniform distribution of the SMD has been observed. Furthermore, the mean axial velocity of the droplets as a function of radial position and reactor pressure is shown. All profiles are axis-symmetric and in consequence, the spray pattern can be considered as rotationally symmetric. Furthermore, a smaller spray angle can be observed when the 21 bar velocity profile is compared with the profile corresponding to 2 bar pressure.

In order to compare the spray quality at different operational conditions, the measured local SMD values are used to determine an integral value $\left(S M D_{\text {int }}\right)$ weighted with the local liquid mass flow $\dot{M}_{\text {local }, i}$ and the cross sectional area $A_{i}$ of the annulus in the spray cone resulting from the distance between two measurement points and the radius of the given measurement position as follows:

$$
S M D_{\text {int }}=\sum\left(\frac{\dot{M}_{\text {local }, i} \cdot A_{i}}{\dot{M}_{\text {tot }} \cdot A_{\text {tot }}} \cdot S M D_{\text {local }, i}\right)
$$

The computed integral value ( $\left.S M D_{\text {int }}\right)$ is also shown in Fig. 7 clearly indicating that a finer spray is obtained at lower reactor pressure for $\mathrm{We}=500$. An increase in pressure at a constant Weber number results in an increase of SMD which is in contradiction with typical correlations [11]. In the present study this effect has been observed for numerous data sets obtained at different values of Weber number while varying the pressure.

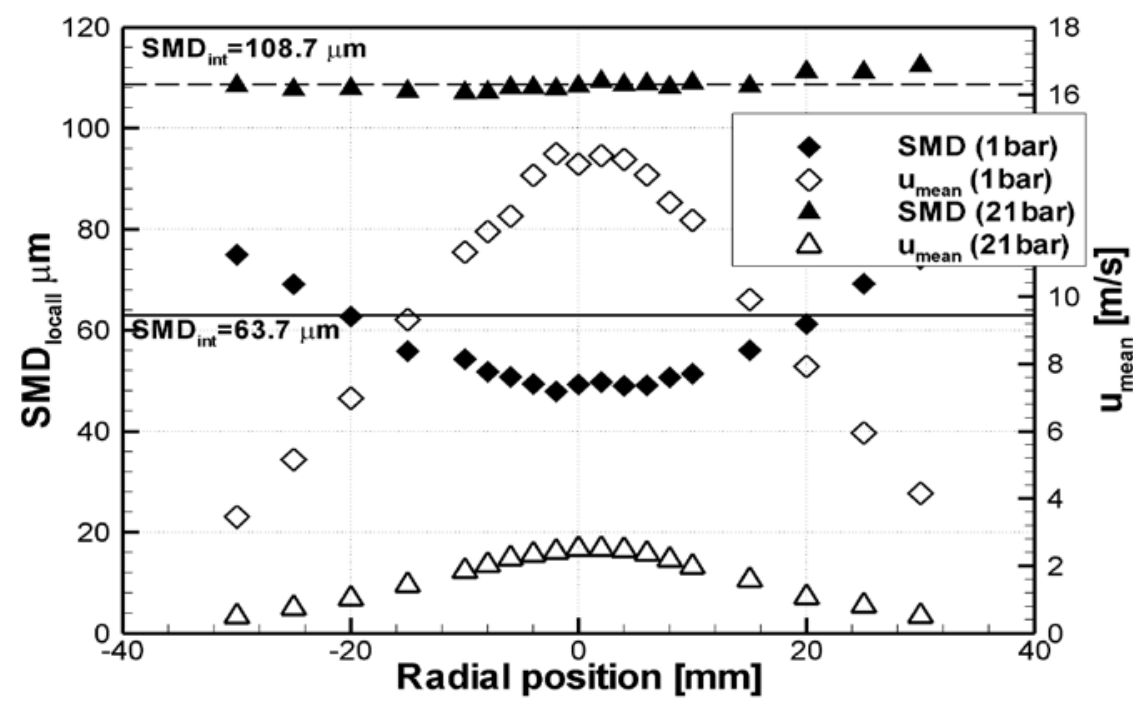

Figure 7: Radial profiles of local SMD and droplet mean axial velocity

Even though the atomization of low-viscous liquids has been thoroughly investigated, due to the rather unconventional approach of keeping the Weber number constant while varying the chamber pressure, the surprising behavior described above has been observed. This clearly illustrates the need for comprehensive systematic investigations on the influence of both operational parameters and fluid properties on twin-fluid atomization using advanced state-of-the art measuring techniques.

\subsection{Kinetic data for particle / droplet conversion at high pressure, high temperature and high heating rates}

As discussed in Section 2.2, kinetic data on particle conversion for biogenic solid and suspension fuels at relevant heating rates, high pressures and temperatures are available to a very limited extent only. To generate a first set of relevant data, the experiments have been conducted under atmospheric 
conditions for a wide spectrum of heating rates, using a thermo-gravimetrical analyzer (TGA), a labscale fluidized bed reactor (FBR) [73] and a drop tube reactor (DTR) [74].

A thermo-balance operated at atmospheric pressure with heating rates up to $1 \mathrm{~K} / \mathrm{s}$ and temperatures up to $1000{ }^{\circ} \mathrm{C}(1273 \mathrm{~K})$ is used to determine kinetic parameters for different fuels. The apparatus consists of a high resolution micro-balance which records the mass loss of the fuel sample caused by gasification of the solid carbon. A fluidized bed reactor provides high heating rates $\left(\sim 10^{4} \mathrm{~K} / \mathrm{s}\right)$, at enhanced mass transfer at up to $1250{ }^{\circ} \mathrm{C}(1523 \mathrm{~K})$ temperature. With this experimental setup, the influence of heating rates on the fuel conversion rate as well as on the products of conversion can be evaluated. Figs. 8 and 9 show the carbon conversion curves obtained using FBR and TGA, both operated at the same conditions (p, T, c). Two different fuels (Petcoke and a wood char) have been gasified in an oxygen-free, $\mathrm{CO}_{2}$ containing atmosphere. The temperature is kept low at $900^{\circ} \mathrm{C}(1173 \mathrm{~K})$ to ensure that the Boudouard reaction is the rate determining step (Regime I, see Section 2.1).

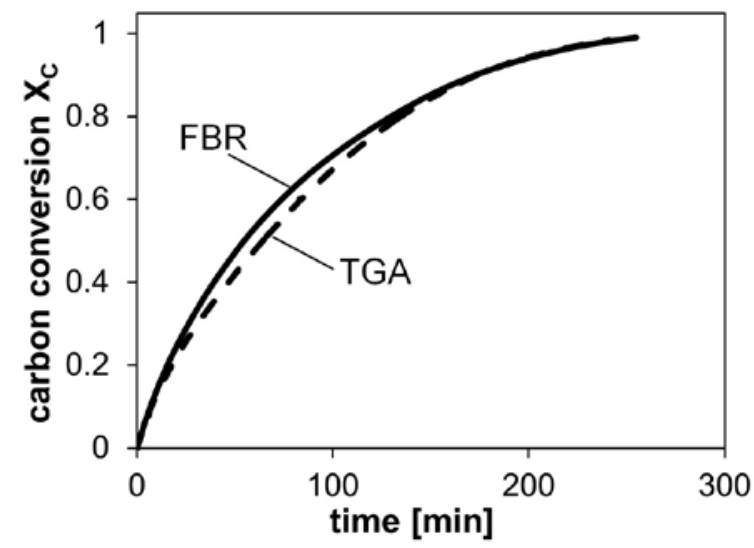

Figure 8: Degree of conversion as a function of time for Petcoke gasification in FBR and TGA at $\mathrm{T}_{\text {gasif }}=900{ }^{\circ} \mathrm{C}(1173 \mathrm{~K})$ and $\mathrm{p}_{\mathrm{CO} 2}=0.75 \mathrm{bar}$; balance gas: nitrogen

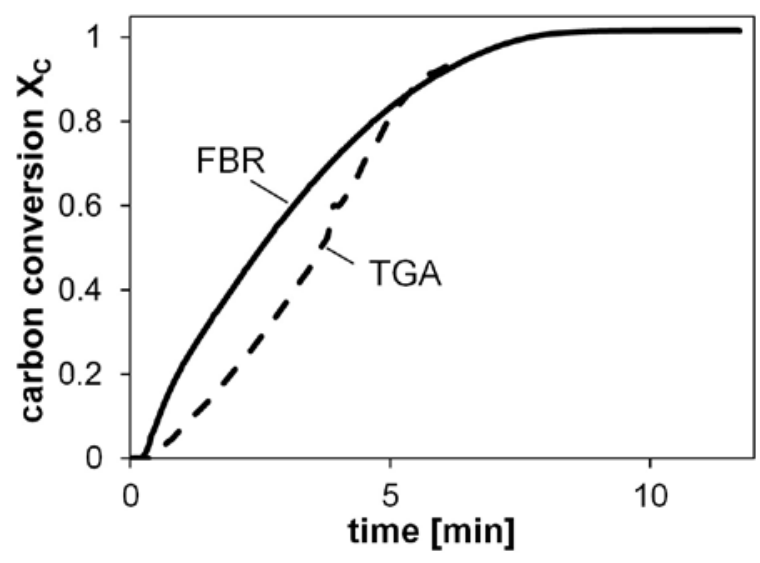

Figure 9: Degree of conversion as a function of time for wood char gasification in FBR and TGA at $\mathrm{T}_{\text {gasif }}=900{ }^{\circ} \mathrm{C}(1173 \mathrm{~K})$ and $\mathrm{p}_{\mathrm{CO} 2}=0.75 \mathrm{bar}$; balance gas: nitrogen

Comparison of the FBR and the TGA results shows no significant difference for Petcoke, despite the very different heating rates that characterize the two reactors. On the other hand, the wood-char shows substantially different behaviour; the high heating rate in the FBR leads to a much more rapid initial conversion (up to around $80 \%$ completion). The wood-char has been produced at $500{ }^{\circ} \mathrm{C}(773 \mathrm{~K})$ pyrolysis temperature and 5 minutes residence time. The detected slow initial conversion in the TGA can be attributed to a change of gas composition in the apparatus during the TGA experiments. Heating of the fuel sample in TGA is carried out under inert conditions. During the heating volatiles are released. Once the set temperature has been reached, a $\mathrm{CO}_{2}$ containing gas is introduced to measure gasification reaction kinetics under isothermal conditions. Thus, the gas atmosphere at the beginning of gasification deviates from the introduced gasification medium as it is being mixed with the volatiles released during the heating. This clearly indicates that in order to comprehend the gasification process, it is necessary to separate pyrolysis from char gasification. Such studies will be conducted under a systematical variation of heating rate, temperature, residence time and pressure. To this end one needs methods to produce secondary chars of low rank coal (lignite) and biomass fuels under pyrolysis conditions typical for a technical gasifiers. This finding is even more important if suspension fuels are applied as in the bioliq ${ }^{\circledR}$ plant. In drop-tube experiments with biomass based slurry, char cenospheres, as shown in Fig. 10, have been observed. The cenospheres are produced during primary pyrolysis of the suspension fuel droplet introduced by a nozzle. They consist of the secondary char particles and a char fraction produced by thermal cracking of the liquid which acts as a binding agent. 


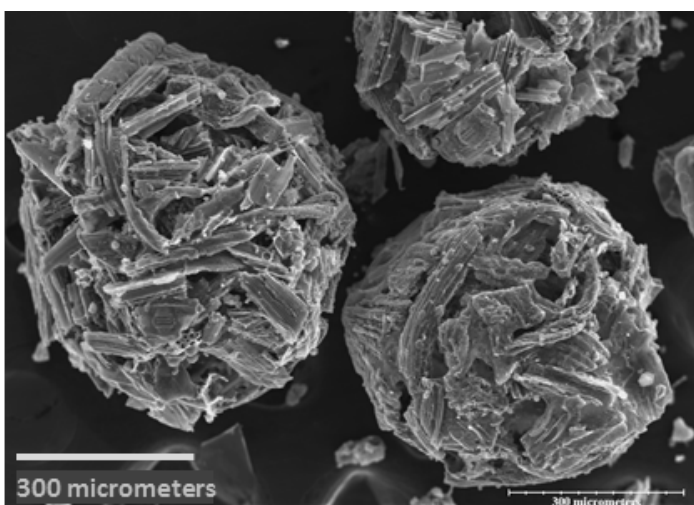

Figure 10: Char cenospheres generated from straw slurry in a drop-tube-reactor (1473 K, 1 bar)
Following the primary and secondary pyrolysis the investigated fuel is subjected to various gasification atmospheres to determine the intrinsic kinetic data. Here, the effects of high temperatures, heating-rates and pressures are of major importance. To account for the effect of high reactor pressure on fuel reaction kinetics, measurements of reaction rates as well as continuous product gas analysis will be carried out in a high-pressure thermo-gravimetric analyzer. Experiments are going to be performed at pressures up to $40 \mathrm{bar}$ with gas atmospheres containing $\mathrm{CO}_{2}, \mathrm{CO}, \mathrm{O}_{2}, \mathrm{H}_{2}$ and $\mathrm{H}_{2} \mathrm{O}$, in order to simulate conditions which are comparable to those occurring in the high pressure pilot-scale bioliq ${ }^{\circledR}$ gasifier (see Section 3.6).

\subsection{Modelling slag properties}

One of the major issues when operating an industrial-scale entrained flow gasifier in slagging mode is to ensure the continuous drainage of the molten slag out of the reactor. Therefore, the necessary process temperature, which determines the efficiency of the gasification process, is often determined by the properties of the slag. A reliable modelling tool with corresponding thermochemical and thermo-physical databases for calculation of chemical and physical (rheological) properties of oxidic gasifier slags in dependence of slag and gas-phase composition, temperature, and pressure enables optimization of the gasifier operation. Such a tool also provides the necessary input data for development of slag sub-model needed in CFD-based numerical simulations (see Section 2.5).

In recent years, the $\mathrm{SiO}_{2}-\mathrm{Al}_{2} \mathrm{O}_{3}-\mathrm{MgO}-\mathrm{CaO}-\mathrm{Na}_{2} \mathrm{O}-\mathrm{K}_{2} \mathrm{O}$ system relevant for the development and production of refractory materials as well as for slag applications has been thermodynamically assessed using all available experimental data on phase equilibria and thermodynamic properties [75, 76]. Self-consistent datasets have been established covering experimental information on all binary, ternary, and quaternary subsystems. The present research aims to extend this database by further oxides relevant to biomass slags (e.g. $\mathrm{P}_{2} \mathrm{O}_{5}, \mathrm{FeO} / \mathrm{Fe}_{2} \mathrm{O}_{3}$ ). Thermodynamic data are derived, whereas missing data are experimentally determined. Activities of different species in the slag and the vapour pressures above the slag are determined by Knudsen Effusion Mass Spectrometry (KEMS) and Molecular Beam Mass Spectrometry (MBMS). Phase transitions, enthalpies, and heat capacities are obtained by means of thermal analysis (DTA, DSC, Drop-Calorimeter). Data from literature and own measurements are being evaluated with the purpose of setting up a consistent solution database. CALPHAD type modelling is used to treat the phase equilibria and the thermodynamic properties of the complex system. The Gibbs energy of the liquid-phase is modelled using a non-ideal associate solution description. The compositions of the pure liquid oxide species are chosen to have two moles of cations per associate thus keeping the successful method of Besmann and Spear [75]. Stoichiometric solids are treated with a simple G(T) function, whereas the compound energy formalism (CEF) is used for solid solutions.

In addition to the thermochemical assessment, an Arrhenius-type model for the calculation of slag viscosities has recently been developed [76]. The model is based on the same structural units, e.g. the associates, as the one for the Gibbs-energy of the melt. Thus, a two-step calculation approach is introduced. First the equilibrium distribution of the associates in a melt with given overall composition is calculated, and then the resulting associate mole fractions are applied in a weighted sum of the logarithms of the associate viscosities as follows:

$$
\ln \eta=\sum_{i}^{N} x_{i} * \ln \eta_{i}=\sum_{i}^{N} x_{i} *\left(A_{i}+\frac{B_{i}}{T}\right)
$$


where $\mathrm{x}_{\mathrm{i}}$ is the molar fraction of structural unit $i ; \mathrm{A}_{\mathrm{i}}$ and $\mathrm{B}_{\mathrm{i}}$ are fitting parameters of structural unit $\mathrm{i}$. Due to the possibility of polymerisation, $\mathrm{x}\left(\mathrm{SiO}_{2}\right)$ is divided into three types of $\mathrm{SiO}_{2}$, e.g.. small, intermediate and large.

First successful applications for the $\mathrm{CaO}-\mathrm{MgO}-\mathrm{Al}_{2} \mathrm{O}_{3}-\mathrm{SiO}_{2}$ quaternary system covering both the charge compensation effect and the lubricant effect (near pure $\mathrm{SiO}_{2}$ ) have been demonstrated (Fig. 11). The charge compensation effect describes the fact, that alumina in combination with an alkali or alkaline earth oxide behaves as a network former resulting in an increased viscosity. The lubricant effect describes the fact that adding small amounts of other oxides to silica causes a steep decrease of viscosity due to depolymerisation. Fig. 11 shows a comparison of experimental literature data and predictions obtained using both the commercially available model implemented in the FactSage software and different versions of the present model, e.g. "Avramov model”, "original Arrhenius model", and "Arrhenius model" which is the latest approach. The current model shows already improvements regarding the prediction of the charge compensation effect and the lubricant effect compared to the original Arrhenius model, but further developments are needed. Furthermore, the database will be extended to a slag-relevant multi-component system covering all oxides present in the thermodynamic database. Therefore, relevant viscosity data will be investigated while missing data will be measured by high temperature rotational viscosimetry. The viscosity data, as well as the phase diagrams concerning bio-ashes, are needed to determine the sticking efficiency of ash particles impacting on the wall either through applying a viscosity criterion or a melting fraction criterion [77]. Such criteria are essential in developing a slag sub-model (see Sections 2.3 and 2.5). Specific experiments are planned to measure the molten slag thermal conductivity.
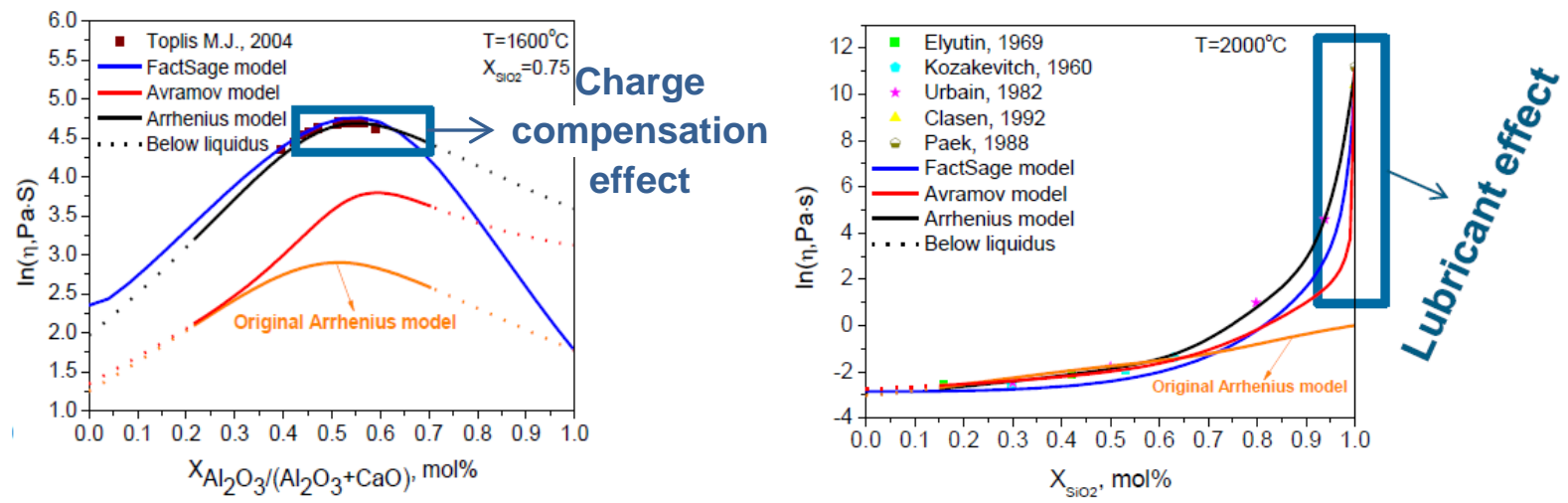

Figure 11: Comparison between experimental data and model predictions in the $\mathrm{SiO}_{2}-\mathrm{Al}_{2} \mathrm{O}_{3}-\mathrm{CaO}$ system (left) and in the $\mathrm{SiO}_{2}-\mathrm{Al}_{2} \mathrm{O}_{3}$ system (right)

\subsection{Modelling gas radiation}

As discussed in Section 2.4, radiative property models which allow for time efficient computation of absorption coefficient and/or emissivity of $\mathrm{CO}_{2} / \mathrm{H}_{2} \mathrm{O} / \mathrm{CO} / \mathrm{H}_{2}$ mixtures at pressures as high as $40-80$ bar are hardly available. They are necessary to reliably model heat transfer in high pressure entrained flow gasification using CFD-based simulation tools. Fig. 12 shows the emissive power calculated by the line-by-line model at atmospheric and 80 bar pressure for a gas mixture which is typical for gasification. Here again, the distinctly different character of high pressure radiation is visible. Due to the stronger line broadening of the absorption lines at elevated pressures, the absorption bands become broader and begin to overlap one another. Moreover, at 80 bar total pressure the emissivity spectrum is smoother if compared to the highly varying spectrum at 1 bar pressure. These effects cause an increase of the total emissivity with the total pressure. 


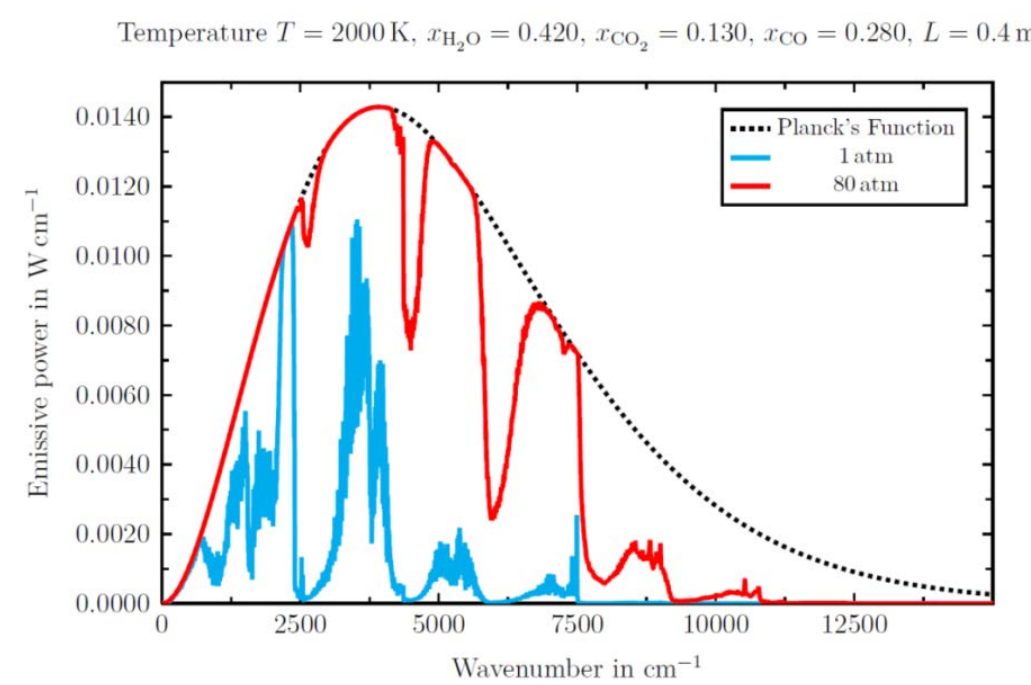

Figure 12: Comparison of spectral emissive power of a gas mixture containing of $\mathrm{H}_{2} \mathrm{O}, \mathrm{CO}_{2}$, and $\mathrm{CO}$ at ambient pressure and $80 \mathrm{~atm}$

The work has begun with a validation of HITEMP [40] and CDSD [41] data-bases using the (atmospheric pressure) $\mathrm{CO}_{2}$ transmissivity data measured by Bharadwaj and Modest [78, 79]. Fig. 13 shows an example of such a comparison while details can be found in Ref. [80]. Good agreement [80] between the measured and computed transmissivities has been obtained (see also Ref. [81, 82]). To extend the confidence in the predictions, additional measurements, spanning the entire spectral region from 1 to 20 microns and at temperatures as high as $1700 \mathrm{~K}$, have been acquired for $\mathrm{CO}_{2} / \mathrm{H}_{2} \mathrm{O} / \mathrm{N}_{2}$ mixtures. The line-by-line calculated spectral and total emissivity are in excellent agreement with the measurements and the largest deviation of $9 \%$ has been observed in case of water vapour total emissivities at $1770 \mathrm{~K}$ temperature [83]. Carbon dioxide emissivities at pressures up to 40 bar have been recently computed [84] using the line-by-line method and appropriate look-up-tables have been generated extending Hottel's graph to 40-bar pressure and validating Leckner's correlations, as shown in Fig. 14. Current work focuses on water vapour at high pressures. Once the scaling with both, temperature and pressure is accurate, a model for predicting total gas emissivity for $\mathrm{H}_{2} \mathrm{O} / \mathrm{CO}_{2} / \mathrm{CO}$ / $\mathrm{H}_{2}$ mixtures will be incorporated in the CFD code.

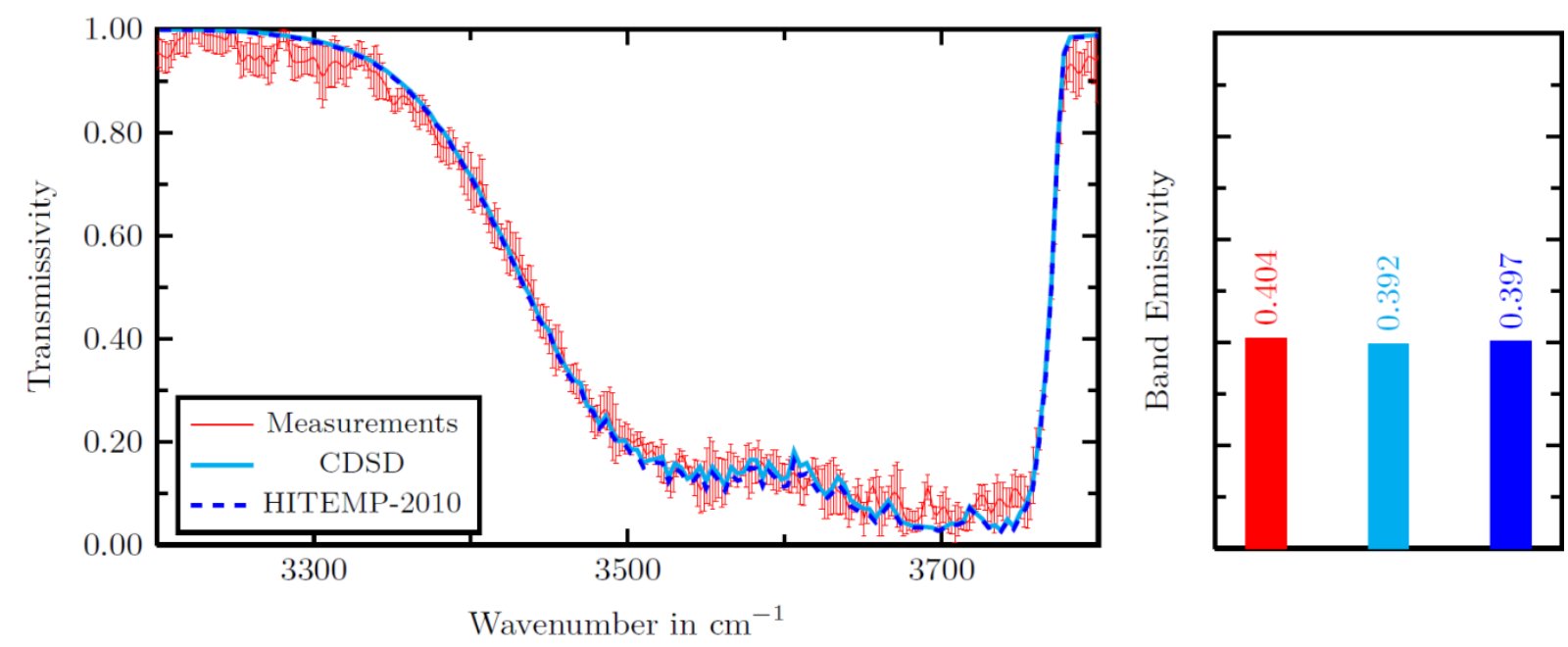

Figure 13: Spectral transmissivity (left) and band emissivity (right) of the $2.7 \mu \mathrm{m}$ band of pure $\mathrm{CO}_{2}$ at $1300 \mathrm{~K}$ and $50 \mathrm{~cm}$ pathlength 


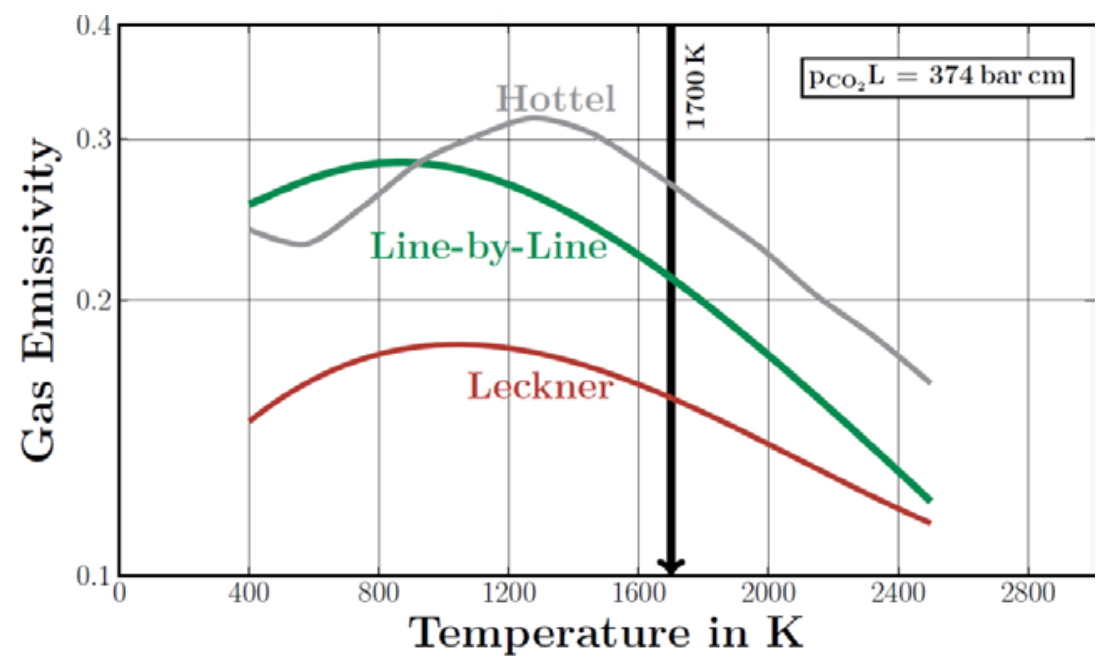

Figure 14: $\mathrm{CO}_{2}$ emissivity at elevated pressure calculated using the line-by-line method, Hottel's graphs [47] extrapolated to high pressure and Leckner's correlations [48]; $1700 \mathrm{~K}$ is a typical gasification temperature

\subsection{Bench-scale experiments on entrained-flow gasification at atmospheric pressure}

The atmospheric bench-scale Research Entrained Flow Gasifier, REGA (Fig. 15) enables a comprehensive experimental investigation at well-defined boundary conditions and flexible independent variation of experimental parameters. The facility operates at $10-15 \mathrm{~kg} / \mathrm{h}$ fuel input (see Table 1 and Fig.15). The reactor consists of a ceramic tube with an inner diameter of $0.28 \mathrm{~m}$ and a length of $3 \mathrm{~m}$. The heat loss of the system is minimized by electric heating of the reactor walls up to $1200{ }^{\circ} \mathrm{C}(1473 \mathrm{~K})$. The burner is equipped with an external mixing nozzle for the atomization of high viscous fuels, such as biomass based slurry generated by pyrolysis of biomass. Along the reactor flanges are mounted for sampling probes and optical access to the reacting gas-phase. The burner is vertically moveable which enables measurement of radial profiles at variable distances from the nozzle. The gasification process can thus be monitored by local temperature and gas-phase composition mapping. After sampling and quenching the gas is analysed to determine the concentrations of $\mathrm{CO}, \mathrm{CO}_{2}, \mathrm{H}_{2}, \mathrm{H}_{2} \mathrm{O}, \mathrm{O}_{2}, \mathrm{CH}_{4}$ and organic carbon $\left(\mathrm{C}_{\text {org }}\right.$ ). The amount of oxygen can be varied from 21 to $90 \mathrm{vol} \%$. Furthermore, optical accessibility of the test rig allows for the application of laser-based measurement techniques.

The REGA experiments aim at an improved understanding of the gasification process of a solid fuel suspended in a liquid carrier medium. Initial measurements have been conducted using a model fuel of well-defined composition rather than complex oil slurries fed to industrial units. For this purpose ethylene glycol has been chosen as its $\mathrm{C}: \mathrm{H}: \mathrm{O}$ ratio is similar to that of biogenic slurry feedstock. Thus, experiments are carried out with glycol and glycol based suspensions of different biogenic chars. The comparison of gas concentrations measured during the gasification of glycol and slurry consisting of $20 \%$ beechwood-char and $80 \%$ glycol is shown in Fig. 16 . Radial profiles of species concentrations have been measured $682 \mathrm{~mm}$ downstream of the burner. The experimental conditions are set up so as to obtain the same residence time and the same adiabatic temperature for both fuels (see Table 1). The spray generated by the employed twin-fluid external-mixing nozzles has been characterized at isothermal conditions measuring the integral Sauter mean diameter $\left(S M D_{\text {int }}\right)$ by means of laser diffraction. At the operating conditions specified in Table 1, the glycol spray features $S M D_{\text {int }}$ of $35 \mu \mathrm{m}$, whereas the slurry spray is characterized by larger droplets with $S M D_{\text {int }}=57 \mu \mathrm{m}$. 
Table 1: Operating conditions of REGA bench-scale gasifier

(Slurry - 20\% beechwood-char and 80\% glycol)

\begin{tabular}{|l|l|l|}
\hline & Glycol & Slurry \\
\hline$\dot{\mathrm{m}}_{\text {fuel }}[\mathrm{kg} / \mathrm{h}]$ & 12.56 & 12.56 \\
\hline $\mathrm{V}_{\text {air }}\left[\mathrm{Nm}^{3} / \mathrm{h}\right]$ & 12 & 12 \\
\hline $\mathrm{x}_{\mathrm{O} 2}[\%]$ & $53.8 \%$ & 55.7 \\
\hline Stoichiometry & 0.57 & 0.51 \\
\hline $\mathrm{V}_{\text {Syngas }}\left[\mathrm{Nm}^{3} / \mathrm{h}\right]$ & 29.5 & 29.5 \\
\hline$T_{\text {ad }}[\mathrm{K}]$ & 1973 & 1973 \\
\hline
\end{tabular}

The radial profiles of methane and organic carbon concentrations given in Fig. 16 clearly show that these intermediates are produced in higher concentrations when the solid-phase is suspended in glycol. When glycol is gasified, methane and organic carbon are measured at the gasifier outlet to be $0.009 \mathrm{vol} \%$ and $37 \mathrm{mg} / \mathrm{Nm}^{3}$, respectively. During slurry gasification $0.065 \mathrm{vol} \%$ methane and 397 $\mathrm{mg} / \mathrm{Nm}^{3}$ organic carbon are detected in the syngas exiting the gasifier. This type of data will be used as a basis for the development of fuel conversion models and for the evaluation of numerical simulation tools for slurry gasification. Experiments for a wide range of fuels (biogenic and fossil) and reactor conditions are in progress.

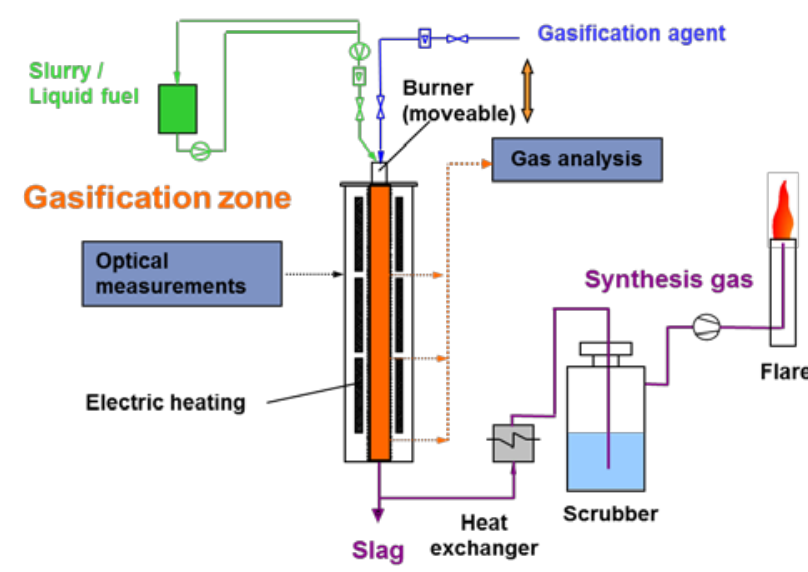

Figure 15: Process flow sheet of the Research Entrained Flow Gasifier (REGA)

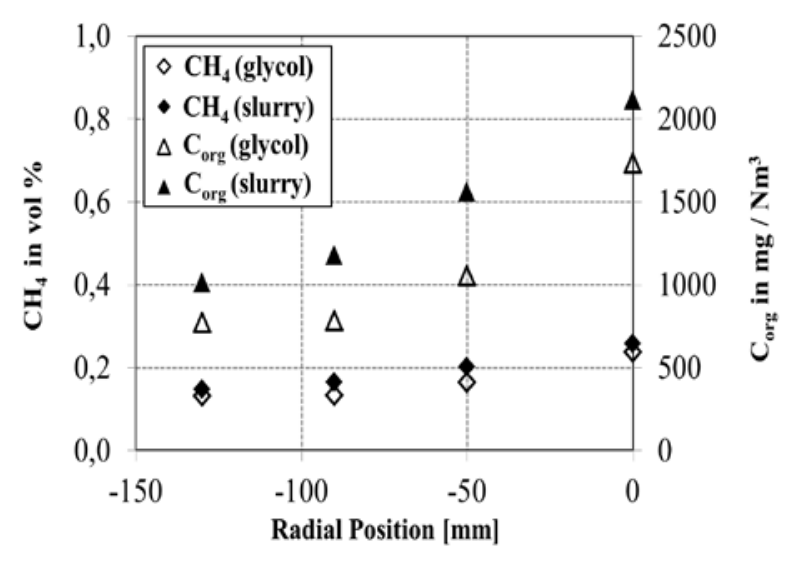

Figure 16: Radial concentration profiles of $\mathrm{CH}_{4}$ and organic carbon when pure glycol and glycol/wood-char slurry are gasified (minus sign means deviation from the gasifier axis which is at zero radial position)

\subsection{Experiments on high pressure gasification (pilot-scale)}

At Karlsruhe Institute of Technology (KIT) the biomass-to-liquid (BtL) pilot plant (bioliq ${ }^{\circledR}$ ) is in operation [2]. The entrained flow gasifier designed for $5 \mathrm{MW}_{\text {th }}$ (e.g. $1000 \mathrm{~kg} / \mathrm{h}$ fuel feed) input which operates at a nominal pressure of 40 or 80 bar (Fig. 17) is fed with pumpable, high viscous slurry produced from straw via flash pyrolysis. The slurry is introduced into the reaction chamber by an oxygen/steam assisted twin-fluid atomizer. The reaction chamber is equipped with a water-cooled membrane wall. The slag is deposited on the refractory lining of the membrane wall and flows downwards to the exit of the gasifier where it is removed from the reactor via a pressure lock (Fig. 17). 
Typical temperatures at the reactor outlet are in the 1300 to $1500 \mathrm{~K}$ range, whereas temperatures in the flame zone may exceed $2000 \mathrm{~K}$ due to the reaction of fuel with oxygen. Overall residence times are of the order of 8 to 10 seconds. The hot syngas enters a water quench zone at the gasifier exit where it is cooled down to about $500 \mathrm{~K}$ before it is processed further. The reactor is equipped with gas and solids sampling probes in the raw syngas duct allowing for an evaluation of the overall performance of the process as function of fuel specification and operational parameters (e.g. stoichiometry, atomization, pressure). Furthermore, an optical access to the reaction zone in the lower part of the reactor is provided (Fig. 17) where the measurement techniques developed within HVIGasTech (Section 3.7) will be applied. The choice of the measurement techniques will be based on the experience gained at the REGA test rig (Section 3.5).

The gasifier is designed to derive global and local mass and energy balances and to observe syngas quality, slagging behavior and other relevant process parameters for a wide spectrum of fuels. The membrane wall of the reactor is segmented (Fig. 17). Each segment is instrumented to derive local energy balances so that the local heat flux to the wall can be estimated using the experimental data. Such heat transfer data are valuable in validating the numerical simulation (Section 3.9).

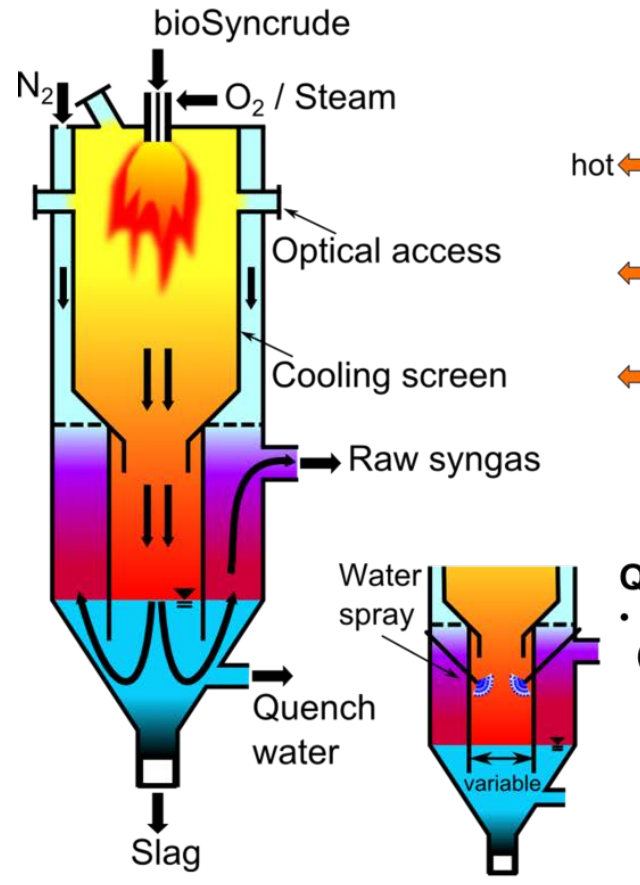

Figure 17: bioliq ${ }^{\circledR}$ high pressure entrained flow gasifier

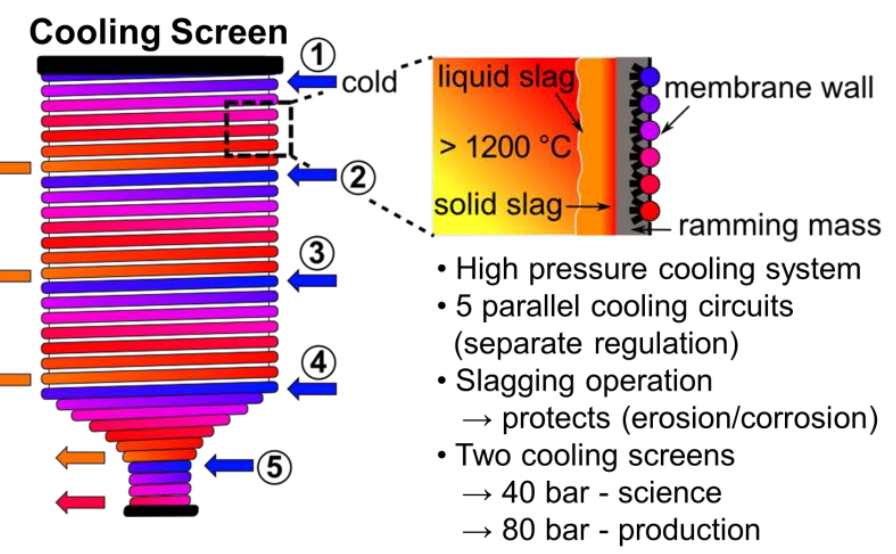

Quench systems

- Different quench systems (full water quench)

$\rightarrow$ Variable tube diameter

$\rightarrow$ Optional quench nozzels

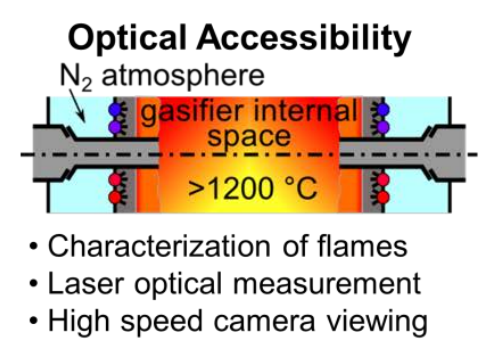

\subsection{Development and application of diagnostic techniques}

Laser-induced incandescence (LII) has been applied to the REGA gasifier operated with slurries of ethylene glycol (EG) and fine particles of biogenic char. LII allows monitoring soot particles of nanometer size while being insensitive to much larger char particles in the $\mu \mathrm{m}$ range. The measurements show that during glycol gasification no soot particles are formed at the conditions studied. However, feeding the gasifier with glycol/biochar slurry leads to soot production. Detected particles have sizes of approx. 15-20 nm and appear in very low concentrations and homogeneous spatial distribution (Fig. 18-bottom). Distinct soot filaments known from rich combustion processes [68] are not identified, at least in the location of optical access $300 \mathrm{~mm}$ downstream the nozzle. While LII is susceptible to nanometer size particles present in the exciting laser sheet, char particles can be 
identified by their luminosity when hotter than the reactor ambience (Fig. 18 top) without using an excitation source. Those travel in larger lumps through the measurement volume and are detectable with the intensified CCD camera employed, but do not respond to laser excitation fluencies used for LII excitation of soot particles. Thus, char particle cloud luminosity appears line-of-sight-integrated with respect to the field of view of the camera, and spatially resolved in both other dimensions.

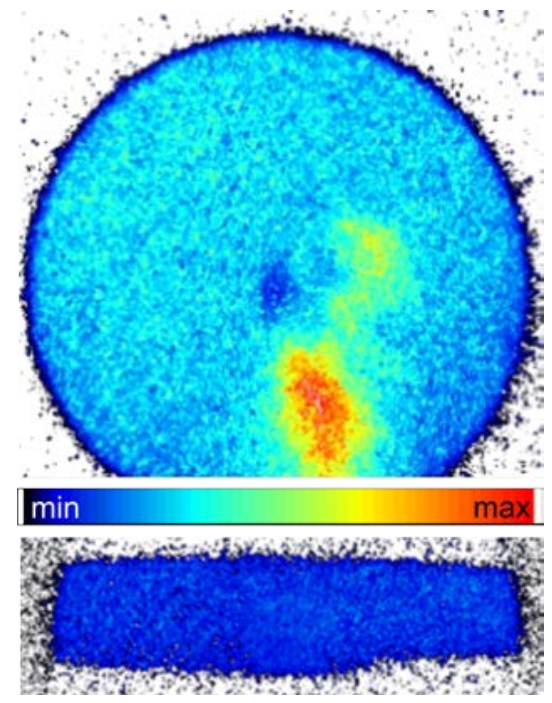

Figure 18: LII measurements during gasification of slurry containing $20 \%$ beechwood-char / 80\% glycol. Reaction zone and char luminosity inside REGA recorded with fish-eye lens without laser illumination (top). Averaged incandescence of soot particles in the laser sheet (bottom) following pulsed excitation

Various measurement techniques beside the here-presented LII are currently being developed and adapted at the REGA such as, Laser-induced breakdown spectroscopy (LIBS) and absorption/emission spectroscopy. Once optimized at atmospheric conditions those measurement techniques will be applied to the pressurized pilot-scale bioliq ${ }^{\circledR}$-gasifier (Section 3.6).

\subsection{Detailed modelling of single physical processes using Large Eddy Simulations (LES)}

The ultimate goal of the application of LES is the development of accurate models for the simulation of unsteady, multiphase flows including heterogeneous reactions in the near-burner region of the gasifier. Nevertheless, LES calculations nowadays are still too expensive to be used as industrial design tool. The major benefit of LES is the numerical investigation of important sub-processes like fuel atomization, turbulent dispersion of fuel and slag particles. In particular, numerical methods for the dispersion and vaporization of the liquid fuel (slurry) droplets are being developed and validated. Data available in the literature, and measurements obtained from the investigations described in Sections 3.1 - 3.7, are used for model verification and validation.

The CFD platform, which is applied and further developed here for LES calculations, is the DLR (Deutsches Zentrum für Luft- und Raumfahrt) combustion code THETA coupled with the DLR Lagrangian spraycode SPRAYSIM [85-87]. It is based on a hybrid Lagrangian-Eulerian method for the simulation of multi-phase reacting flows such as those encountered in gasification processes. A description of the capabilities and numerical methods of THETA are given by [88]. A specification of the RANS and LES turbulence models which are available in THETA can be found in [89]. In the present work a direct detailed chemistry model, which solves a transport equation for each of the reaction species is employed in conjunction with a stiff chemistry solver [90]. Thus, for example, 
calculations based on different ethylene glycol chemical reaction models [91] enable identifying the most adequate model for the mixture, temperature and pressure conditions encountered in the gasifier.

The SPRAYSIM code is equipped with various models for numerical simulations of liquid fuel primary and secondary atomization, droplet transport and vaporization. Concerning vaporization, several models are available for homogeneous mixtures and discrete species as well as the effective Continuous Thermodynamics Model CTM are included in SPRAYSIM [92]. Additionally, models for the vaporization of emulsions and suspensions are being developed. SPRAYSIM/CTM method was applied to compare the droplet vaporization of glycol used as a model fuel for initial gasification studies in the present work with other conventional fuels and is shown in Fig. 19 where the droplet vaporization of different fuels is considered. It is obvious that glycol evaporates slowly compared to the other fuels. Furthermore, non-reacting computation of a glycol spray introduced into the geometry of the REGA reactor (Section 3.5) with heated walls has been conducted to observe the droplet trajectories and the droplet size variation during evaporation (Fig. 20). The spray injected into the reactor is described with the droplet size distribution measured by means of laser diffraction spectrometry using the REGA nozzle (see Section 3.1). This non-reacting computation shows that a substantial amount of fuel has vaporized in the early stages of the droplet trajectories, which is favourable for ignition. The trajectories also show the effect of turbulent dispersion.

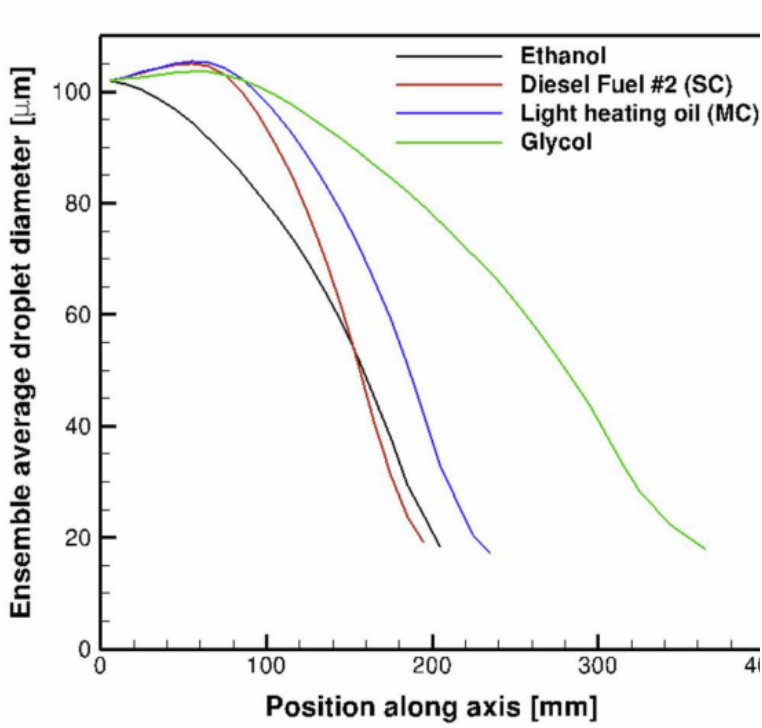

Figure 19: Spray evaporation of different fuels

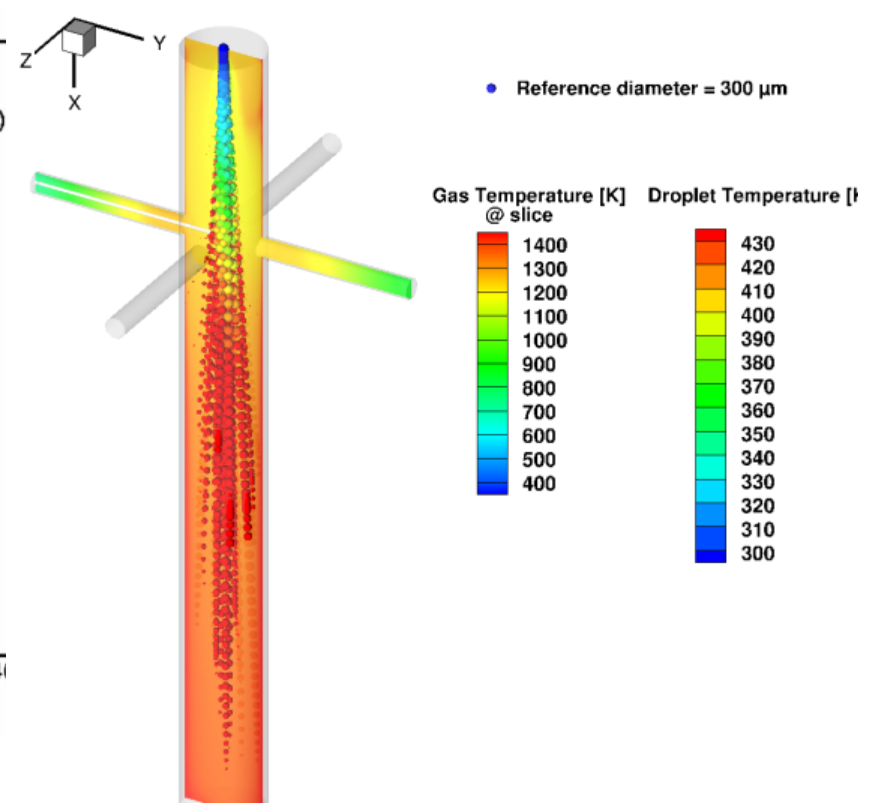

Figure 20: Glycol droplet temperature along the trajectories and gas temperature in the axial plane of the REGA test-rig.

\subsection{RANS simulations of entrained-flow gasification}

A CFD model has been developed to simulate gasification of glycol in the REGA bench-scale gasifier. The model is based on the RANS approach in which steady-state balance equations for mass, momentum, energy and species are solved using a finite volume solver. The turbulence is taken into account solving for the Favre averaged variables and the closure is achieved using the Reynolds Stress Model [93]. The heat transferred to the walls is calculated considering convective and radiative exchange locally, at each cell adjacent to a wall. The convective heat transfer is calculated using wall functions [94] while the incoming radiation at each position on the wall is calculated solving the Radiative Transfer Equation (RTE) using the Discrete Ordinate (DO) method. Trajectories of glycol droplets are computed using Lagrangian tracking with turbulent fluctuations included. Droplet size distribution used in the computation was measured for the experimentally investigated nozzle and operating conditions, as described in Section 3.1. 
After being heated up, glycol droplets evaporate producing vapour which in the model decomposes to $\mathrm{CO}, \mathrm{CH}_{4}, \mathrm{H}_{2} \mathrm{O}$ and $\mathrm{H}_{2}$. Two mechanisms have been used for gas-phase kinetics and in Figs. 21 and 22 these are marked as $\mathrm{M}-1$ and $\mathrm{M}-2$. In the first mechanism (M-1) methane is oxidized according to the 4-step mechanism [95] which is complemented by the water-gas-shift reaction. In the second mechanism (M-2) methane oxidation proceeds following the 2-step mechanism [96]. The influence of the fluctuations and un-mixedness on reaction rates is calculated using the Eddy Dissipation Concept (EDC) [97, 98,99].

In Figs. 21 and 22 the results of the calculations are compared with the measurements performed in the REGA facility (see Section 3.5) when pure glycol is gasified for operating conditions listed in Table 1. Fig. 21 shows the comparison for the temperature profile taken at $\mathrm{x}=680 \mathrm{~mm}$ traverse downstream of the burner while Fig. 22 reports the comparison for the radial concentration profile of $\mathrm{H}_{2}$, $\mathrm{CO}$ and $\mathrm{CO}_{2}$ at the same measurement position. Both mechanisms provide a good agreement as far as the measured temperatures are concerned. Differences can be seen in the prediction of the main species concentrations. Although the differences are not exceedingly large, a better agreement can be found when the 4-steps (M-1) mechanism is used. A deeper analysis of the results shows that the local stoichiometry and the rate of the water gas shift reaction are among the most important modelling parameters affecting the quality of the predictions. The local stoichiometry is determined by the amount of glycol evaporated and by the mixing between the glycol jet, the coaxial gas flow and the outer gas recirculation zone. It has been found that the RSM turbulence model produces a good prediction of the mixing process and of the recirculation zone. The evaporation rate is strongly dependent on the properties of the glycol, mainly the saturated vapour pressure and the molecular diffusion of the evaporated gas.

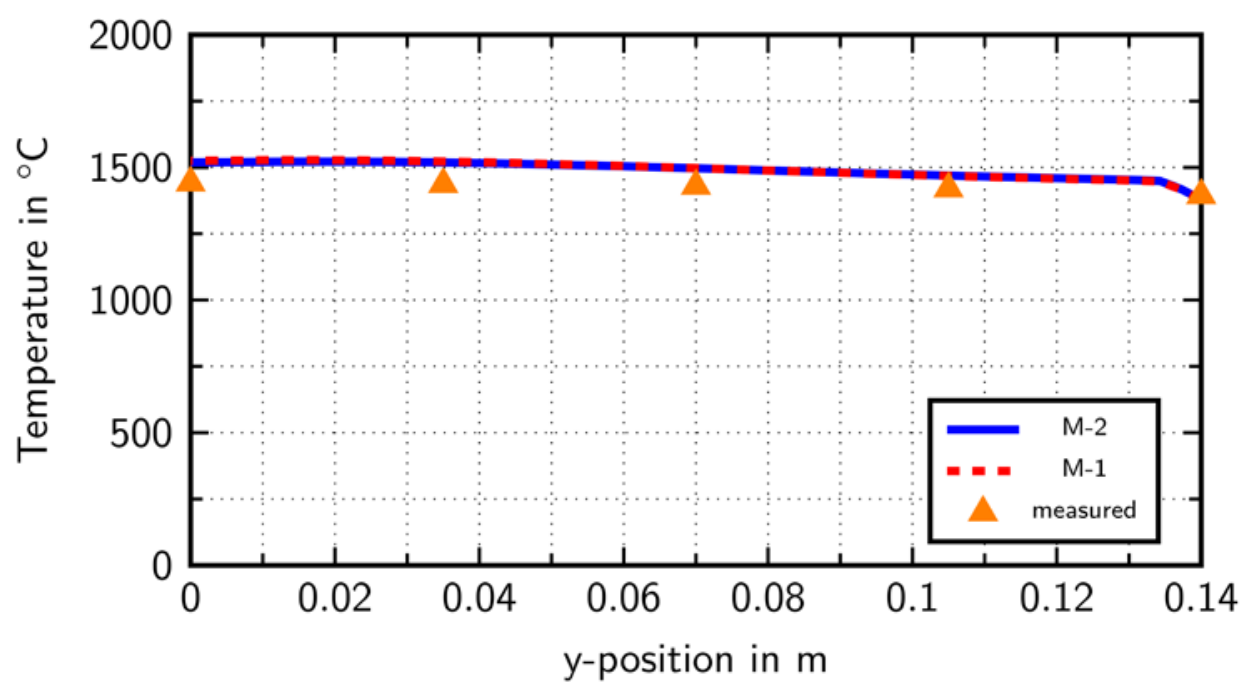

Figure 21: Glycol gasification - radial temperature profile at the distance of $680 \mathrm{~mm}$ downstream of the burner 


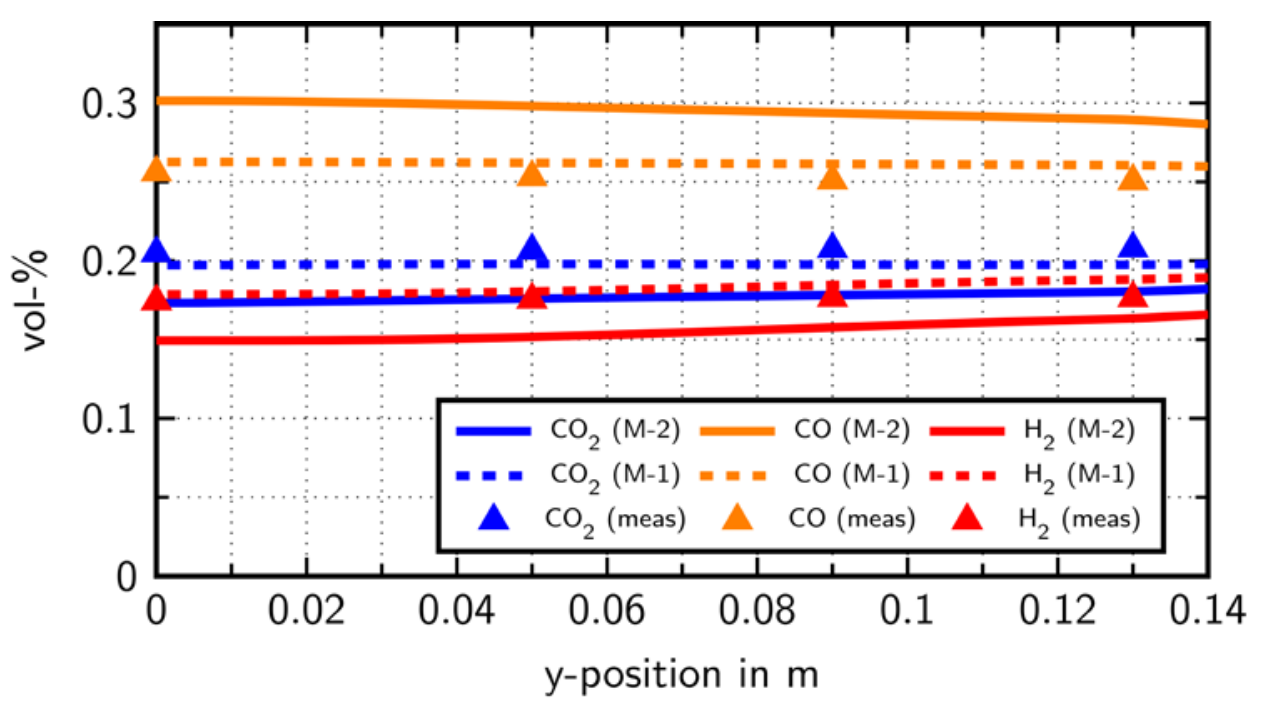

Figure 22: Glycol gasification - measured and predicted $\mathrm{H}_{2}, \mathrm{CO}$ and $\mathrm{CO}_{2}$ volume fractions at $680 \mathrm{~mm}$ downstream of the burner

Further development of the present model to incorporate realistic models of slurry atomization, evaporation and heterogeneous reaction of secondary char produced during pyrolysis step in an entrained flow gasifier at high pressure will be based on the findings and theoretical models developed from the research activities described in the Sections 3.1 - 3.8. Therewith, a knowledge-based comprehensive engineering tool for the quantitative description of the total gasification process enabling the design and scale-up of technical entrained flow gasifiers for a wide range of feedstock will be developed and validated using unique data sets collected at pilot-scale and at high pressure.

\section{FINAL REMARKS}

The reactor design and the process optimization for complex low-grade fuels such as e.g. biomass-based chars, oils and suspension fuels (slurries) is very challenging due to the lack of in detail understanding of the different thermo-chemical process steps governing such reacting high-pressure multiphase systems.

Various knowledge gaps exist in understanding twin-fluid atomization of high viscous non-Newtonian suspension fuels as well as homogeneous and heterogeneous reaction mechanisms and ash/slag formation at pressures as high as 80 bar. Although methods for computing radiative heat transfer at atmospheric pressure exist and their application to high pressure is rather straight forward, there is hardly any information available concerning absorption coefficients and emissivities of $\mathrm{CO}_{2} / \mathrm{H}_{2} \mathrm{O} / \mathrm{CO} / \mathrm{H}_{2}$ mixtures with suspended oil/solid particles, which are typical for the gasification process. In order to understand the complex interactions between the mentioned processes during entrained-flow gasification, experimental investigations under systematic variation of fuel specification and process parameters are necessary. Detailed process mapping based on experimental data from lab- to pilot-scale is crucial in order to develop a detailed process understanding and provide a comprehensive data basis for the validation of numerical simulations. This also implies the development of advanced optical and laser-based measurement techniques applicable under the harsh conditions of entrained flow gasifiers. In the present paper the research activities under the umbrella of the Helmholtz Virtual Institute for Gasification Technology (HVIGasTech) are shown. They are dedicated to the mathematical modeling of the entrained-flow gasification process, aiming at the development of a CFD-based software package for optimization and scale-up of the bioliq ${ }^{\circledR}$ entrained flow gasifier in particular, and high-pressure entrained-flow gasification of low-grade feedstock in general. 


\section{ACKNOWLEDGEMENT}

The authors gratefully acknowledge the financial support by the Helmholtz Association of German Research Centres (HGF) in the frame of the Helmholtz Virtual Institute for Gasification Technology - HVIGasTech (VH-VI-429)

\section{REFERENCES}

[1] Higman C. State of the Gasification Industry - the Updated Worldwide Gasification Database. Gasification Technologies Conference, Colorado Springs, CO, October 16, 2013 (http://www.gasification.org/database1/search.aspx)

[2] Dahmen N, Dinjus E, Kolb T, Arnold U, Leibold H, Stahl R. State of the Art of the Bioliq ${ }^{\circledR}$ Process for Synthetic Biofuels Production. Environmental Progress \& Sustainable Energy 2012; 31 (2): 176-81

[3] Kolb T, Eberhard M. BtL - the bioliq Process at KIT. DGMK- Conference „New Technologies \& Alternative Feedstocks in Petrochemistry and Refining, Dresden, 9.-11. Oktober 2013. DGMK Tagungsbericht 2013-2, S. 81-87, ISBN 978-3-941721-32-6

[4] Mancini M, Weber R, Weigand P, Leuckel W, Kolb T. Design of the entrained flow reactor for gasification of biomass based slurry. 26. Deutscher Flammentag - Verbrennung und Feuerung, Duisburg, 11.-12. September 2013. VDI-Berichte 2161 (2013) 625-634

[5] Sänger A, Kolb T, Mancini M, Weber R, Weigand P:

The bioliq ${ }^{\circledR}$ Entrained Flow Gasifier for Biomass Based Slurry - Design and Operation.

38th International Conference on Clean Coal \& Fuel Systems, Clearwater, FL, USA; 2.-6. Juni 2013

[6] Scholz R, Beckmann M, Pieper C, Muster M, Weber R. Considerations on providing the energy needs using exclusively renewable sources: Energiewende in Germany. Renewable and Sustainable Energy Reviews 2014; 35: 109-25.

[7] http://www.hvigastech.org/

[8] Jakobs T, Djordjevic N, Fleck S, Mancini M, Weber R, Kolb T. Gasification of high viscous slurry; R\&D on atomization and numerical simulation. Applied Energy 2012; 93: 449-56.

[9] Dahmen N, Henrich E, Dinjus E, Weirich F. Energy, Sustainability and Society, 2:2 (13 February 2012) 1-44.

[10] Tremel A, Haselsteiner T, Kunze C, Spliethoff H. Experimental investigation of high temperature and high pressure coal gasification. Applied Energy 2012; 92: 279 - 85.

[11] Lefebvre AH. Atomization and sprays. New York: Hemisphere Pub. Corp. 1989.

[12] Sayre AN, Dugué J, Weber R, Domnick J, Lindenthal A. Characterisation of semi-industrial-scale fuel-oil sprays issued from a Y-jet atomiser. Journal of the Institute of Energy, June 1994, 67, pp.7077.

[13] Tamura M, Constantini S, di Fuccia G, Giordano P, Weber R. Development of a library of atomizers for industrial oil fired burners. Ijmuiden, July 2001, IFRF Doc. No. F67/y/2.

[14] Elkotb MM, El-Sayed Mahdy MA, Montaser, ME. Investigation of External Mixing Air Blast Atomizers. ICLASS-82, $2^{\text {nd }}$ International Conference on Liquid Atomization and Spray Systems, Madison, USA, 1982.

[15] Yu TU, Beer JM. Atomization of Coal Water Fuel at Elevated Pressure. $14^{\text {th }}$ International Conference on Coal and Slurry Technology Clearwater, Florida 1989.

[16] Rizk NK, Lefebvre AH. Spray Characteristics of Plain-Jet Airblast Atomizers. Journal of Engineering for Gas Turbines and Power 1984; 106: 634-38.

[17] Mansour A, Chigier N. Air-blast atomization of non-Newtonian liquids. J. Non-Newtonian Fluid Mech. 1995; 58: 161-94.

[18] Mulhem B. Einfluss der Festoffbelandung (Größe und Konzentration) auf die Zerstäubung von Suspensionen mittels einer extern mischenden Zweistoffdüse, Dissertation Universität Bremen 2004.

[19] Yu TU, Kang SS, Beer JM. Secondary Atomization of Coal-Water Fuels for Gas Turbine Applications. MIT Energy Laboratory Report No. MIT-EL 88-008, 1988.

[20] Smith CF, Sojka PE, Lefebvre AH. Plain-Jet Airblast Atomization of Coal-Water Slurry Fuels. SAE Paper No. 852085, 1985. 
[21] Cetin E, Gupta R, Moghtaderi B. Effect of pyrolysis pressure and heating rate on radiata pine char structure and apparent gasification reactivity. Fuel 2005; 84 (10): 1328 -34.

[22] Higman C, van Burgt M. Gasification. 2. Aufl. Amsterdam: Gulf Professional Pub./Elsevier Science; 2008.

[23] Ahn DH, Gibbs BM, Ko KH, Kim JJ. Gasification kinetics of an Indonesian sub-bituminous coalchar with $\mathrm{CO}_{2}$ at elevated pressure. Fuel 2001; 80: 1651-58.

[24] Kajitani S, Hara S, Matsuda H. Gasification rate analysis of coal char with a pressurized drop tube furnace. Fuel 2002; 81: 539-46.

[25] Laurendeau NM. Heterogeneous Kinetics of Coal Char Gasification and Combustion. Prog. Energy Comb. Sci. 1978; 4: 221-70.

[26] Roberts D, Harris D. Char Gasification with $\mathrm{O}_{2}, \mathrm{CO}_{2}$ and $\mathrm{H}_{2} \mathrm{O}$ : Effects of pressure on Intrinsic Reaction Kinetics, Energy \& Fuels 2000; 14 (2) 483-89.

[27] Di Blasi C. Combustion and gasification rates of lignocellulosic chars. Progress in Energy and Combustion Science 2009; 35 (2): 121-40.

[28] Ifran C F, Usman MR, Kusakabe $\mathrm{K}$. Coal gasification in $\mathrm{CO}_{2}$ atmosphere and its kinetics since 1948. A brief review. Energy 2011; 36: 12 - 40.

[29] Chmielniak T, Sciazko M, Tomaszewicz G, Tomaszewicz M. Pressurized CO2-enhanced gasification of coal. Thermodynamical and kinetic modeling. Journal of Thermal Analysis and Calorimetry, (2014) 117: 1479-1488.

[30] Wall TF, Liu G-S, Wu H-W, Roberts DG, Benfell K E, Gupta, S. et al. The effects of pressure on coal reactions during pulverised coal combustion and gasification. Progress in Energy and Combustion Science 2002; 28: 405 - 33.

[31] Matsuoka K, Akiho H, Xu W, Gupta R, Wall TF, Tomita A. The physical character of coal char formed during rapid pyrolysis at high pressure. Fuel 2005; 84 (1): 63-9.

[32] Willenborg W. Untersuchungen zur Alkalireinigung von Heißgasen für Anlagen mit Kohlenstaub-Druckfeuerung. PhD Thesis, RWTH Aachen, Germany, 2003.

[33] Yazhenskikh E, Hack K, Müller M. Critical thermodynamic evaluation of oxide systems relevant to fuel ashes and slags, Part 5: Potassium oxide-alumina-silica. Calphad 2011; 35: 6-19.

[34] Peter R. Thermochemische Untersuchungen zum Einfluss der Erdalkalien in oxidischen Schlacken. PhD Thesis, RWTH Aachen, Germany, 2013.

[35] Vargas S, Frandsen FJ, Dam-Johanson K. Rheological properties of high-temperature melts of coal ashes and other silicates. Progress in Energy and Combustion Science 2001; 27: 237-426.

[36] Shaw HR. Viscosities of magmatic silicate liquids: An empirical method of prediction. Am. J. Sci. 1972; 272: 870-93.

[37] Urbain G. Viscosity of silicate melts. Trans. J. Br. Ceram. Soc. 1981; 80: 139-41.

[38] Decterov SA, Grundy AN, Pelton AD. A model and database for the viscosity of molten slags. Proc. of the VIII International Conference on Molton Slags, Fluxes and Salts, Santiago, Chile, 2009, 423-31.

[39] Nentwig T. Experimentelle Bestimmung und numerische Simulation von Viskositäten in Schlackesystemen unter Vergassungsbedingungen, PhD Thesis, RWTH Aachen, Germany, 2011.

[40] Rothman L S, Gordon I E, Barber RJ, Dothe H, Gamache R, Goldman A. et al. HITEMP, the high-temperature molecular spectroscopic database. Journal of Quantitative Spectroscopy and Radiative Transfer 2010; 111: 2139 - 50.

[41] Tashkun S, Perevalov V, Teffo JL, Bykov A, Lavrentieva N. CDSD-1000, the high-temperature carbon dioxide spectroscopic databank. Journal of Quantitative Spectroscopy and Radiative Transfer 2003; 82: 165 - 96

[42] Grosshandler W L. RADCAL: A Narrow-Band Model for Radiation Calculations in a Combustion Environment. National Technical Information Service (NTIS) 1993; Technical Note 1402 [43] Edwards D, Irvine T F, Hartnett J P. Molecular Gas Band Radiation. Advances in heat transfer 1976; 12: 115 - 193.

[44] Edwards D, Balakrishnan A. Thermal radiation by combustion gases. International Journal of Heat and Mass Transfer 1973; 16: 25 - 40.

[45] Lallemant N, Weber R. A computationally efficient procedure for calculating gas radiative properties using the exponential wide band model. Int. Journal Heat Mass Transfer 1996; 39: 3273-86. 
[46] Lallemant N, Sayre A, Weber R. Evaluation of emissivity correlations for $\mathrm{H}_{2} \mathrm{O}-\mathrm{CO}_{2}-\mathrm{N}_{2} / \mathrm{Air}$ mixtures and coupling with solution methods of the radiative transfer equation. Prog. Energy. Comb. Sci. 1996; 22: 543-74.

[47] Hottel H, Sarofim A. Radiative Transfer, MacGraw-Hill, 1967.

[48] Leckner B. The spectral and total emissivity of carbon dioxide. Combustion and Flame 1971; 17: 37-44.

[49] Leckner B. Spectral and total emissivity of water vapour and carbon dioxide. Combustion and Flame 1972; 19: 33-48.

[50] Abani N, Ghoniem AF. Large eddy simulations of coal gasification in an entrained flow gasifier. Fuel 2013; 104: 664-80.

[51] Schaffel N, Mancini M, Szlek A, Weber R. Mathematical modeling of MILD combustion of pulverized coal. Combustion and Flame 2009; 156: 1771-84.

[52] Weiland F, Hedman H, Marklund M, Wiinikka H, Ohrman O, Gebart R. Pressurized Oxygen Blown Entrained-Flow Gasification of Wood Powder. Energy Fuels 2013; 27 (2): 932-41.

[53] Ogi T, Nakanishi M, Fukuda Y, Matsumoto K. Gasification of oil palm residues (empty fruit bunch) in an entrained-flow gasifier. Fuel 2013; 104: 28-35.

[54] Öhrman OGW, Weiland F, Pettersson E, Johansson A-C, Hedman H, Pedersen M. Pressurized oxygen blown entrained flow gasification of a biorefinery lignin residue. Fuel Processing Technology 2013; 115: 130-38.

[55] Hernández JJ, Aranda G, Barba J, Mendoza JM. Effect of steam content in the air-steam flow on biomass entrained flow gasification. Fuel Processing Technology 2012; 99: 43-55.

[56] Hernández JJ, Aranda G, Bula A. Gasification of biomass wastes in an entrained flow gasifier: Effect of the particle size and the residence time. Fuel Processing Technology 2010; 91: 681-92.

[57] Risberg M, Gebart R. Numerical modeling of counter-current condensation in a Black Liquor Gasification plant. Applied Thermal Engineering 2013; 58: 327-35.

[58] Lewis AD, Fletcher EG, Fletcher TH. $\mathrm{CO}_{2}$ Gasification Rates of Petroleum Coke in a Pressurized Flat-Flame Burner Entrained-Flow Reactor. Energy \& Fuels 2014; 28: 4447 - 57.

[59] Tremel A, Spliethoff H. Gasification kinetics during entrained flow gasification - Part II: Intrinsic char reaction rate and surface area development. Fuel 2013; 107: 653-61.

[60] Li S, Whitty KJ. Physical phenomena of char-slag transition in pulverized coal gasification. Fuel Processing Technology 2012; 95: 127-36.

[61] Sun K, Sur R, Chao X, Jeffries JB, Hanson RK, Pummill RJ, Whitty KJ. TDL absorption sensors for gas temperature and concentrations in a high-pressure entrained-flow coal gasifier. Proceedings of the Combustion Institute 2013; 34 (2): 3593-601.

[62] Brüggemann P, Baitalow F, Seifert P, Meyer B, Schlichting H. Behaviour of heavy metals in the partial oxidation of heavy fuel oil. Fuel Processing Technology 2010; 91 (2): 211-17.

[63] Morehead H. Siemens Gasification and IGCC Update. Presented at PowerGEN International Orlando, FL December 3, 2008.

[64] Carlsson P, Wiinikka H, Marklund M, Grönberg C, Pettersson E, Lidman M, Gebart R. Experimental investigation of an industrial scale black liquor gasifier. 1. The effect of reactor operation parameters on product gas composition. Fuel 2010; 89 (12): 4025-34.

[65] Wehr L, Meier W, Kutne P, Hassa C. Single-pulse 1D laser Raman scattering applied in a

gas turbine model combustor at elevated pressure. Proceedings of the Combustion Institute 2007; 31: 3099-3106.

[66] Lammel O, Geigle KP, Lückerath R, Meier W, Aigner M. Investigation of Soot Formation and Oxidation in a High-Pressure Gas Turbine Model Combustor by Laser Techniques. ASME Turbo Expo 2007: Power for Land, Sea, and Air, Volume 2: Turbo Expo 2007. Montreal, Canada, May 1417, 2007.

[67] Lückerath R, Meier W, Aigner M. FLOX ${ }^{\circledR}$ Combustion at High Pressure with Different Fuel Compositions. Journal of Engineering for Gas Turbines and Power 2008; 130: 011505-1.

[68] Lückerath R, Lammel O, Stohr M, Boxx I, Stopper U, Meier W, et al. Experimental Investigations of Flame Stabilization of a Gas Turbine Combustor. ASME 2011 Turbo Expo: Turbine Technical Conference and Exposition, Volume 2: Combustion, Fuels and Emissions, Parts A and B Vancouver, British Columbia, Canada, June 6-10, 2011. 
[69] Geigle KP, Hadef R, Meier W. Soot formation and flame characterization of an aero-engine model combustor at elevated pressure. Proc. ASME Turbo Expo 2013, Power for Land, Sea and Air, 03.-07.06. 2013, San Antonio, Texas, USA, GT2013-95316.

[70] Gounder JD, Kutne P, Meier W. Development of a laser-induced plasma probe to measure gas phase plasma signals at high pressures and temperatures. Spectrochemica Acta 2012; Part B 74-75: 66-73

[71] Jakobs T, Djordjevic N, Fleck S, Zarzalis N, Kolb T. Influence of Ambient Pressure on Twin Fluid Atomization - R\&D Work for high pressure entrained flow gasification. ICLASS 2012, $12^{\text {th }}$ Triennial International Conference on Liquid Atomization and Spray Systems, Heidelberg, Germany 2012

[72] Lasheras JC, Villermaux E, Hopfinger EJ. Break-up and atomization of a round water jet by a high-speed annular air jet. Journal of Fluid Mechanics 1998; 357: 351-79.

[73] Haustein HD, Goevert B, Christ D, Habermehl M, Hatzfeld O, Kneer R. Small Scale Fluidized Bed Reactor for Investigation of Particle Reaction Rates: Char Combustion and the Boudouard Reaction (Paper No. 2825594). $6^{\text {th }}$ European Combustion Meeting (ECM 2013), Malmoe, Sweden, 2528 June, 2013

[74] Worringer G, Reimert R. Ermittlung des Rußumsatzes in-situ unter Flugstromvergasungsbedingungen. Tagungsband 25. Deutscher Flammentag, Karlsruhe, 2011, 589592

[75] Besmann TM, Spear KE. Thermodynamic modeling of oxide glasses. J. Am. Ceram. Soc. 2002; 85 (12): 2887-94.

[76] Hack K, Jantzen T, Müller M, Yazhenskikh E, Wu G. A novel thermodynamic database for slag systems and refractory materials. in Proceedings of the $5^{\text {th }}$ International Congress on the Science and Technology of Steelmaking, ICS 2012, Dresden, Germany, 2012.

[77] Weber R, Poyraz Y, Beckmann AM, Brinker S. Combustion of biomass in jet flames. Proceedings of the Combustion Institute, 35 (3) (2014) 2749-2758.

[78] Bharadwaj S P, Modest M F, Riazzi R J. Medium resolution transmission measurements of water vapor at high temperature. Journal of Heat Transfer 2006; 128: 374-81.

[79] Bharadwaj S P, Modest MF. Medium resolution transmission measurements of $\mathrm{CO}_{2}$ at high temperature - an update. Journal of Quantitative Spectroscopy and Radiative Transfer 2007; 103: 146 -55 .

[80] Alberti M, Weber R, Mancini M, Modest MF. Comparison of models for predicting band emissivity of carbon dioxide and water vapour at high temperatures. Journal of Heat and Mass Transfer 2013; 64: 910-25.

[81] Becher V, Clausen S, Fateev A, Spliethoff H. Validation of spectral gas radiation models under oxyfuel conditions. Part A: Gas cell experiments. International Journal of Greenhouse Gas Control 2011; 5 (1): 76 - 99.

[82] Evseev V, Fateev A, Clausen S. High-resolution transmission measurements of $\mathrm{CO}_{2}$ at high temperatures for industrial applications. Journal of Quantitative Spectroscopy and Radiative Transfer 2012; 113 (17): 2222 - 33.

[83] Alberti M, Weber R, Mancini M, Fateev A, Clausen S. Validation of HITEMP-2010 for Carbon Dioxide and Water Vapour at high temperatures and atmospheric pressures. Journal of Quantitative Spectroscopy \& Radiative Heat Transfer 2015; 157: 14-33.

[84] Alberti M, Weber R, Mancini M. Re-creating Hottel's emissivity charts for carbon dioxide and extending them to 40 bar pressure using HITEMP-2010 data base. Combustion and Flame 2015; 162 (3): $597-12$.

[85] Di Domenico M, Le Clercq P, Rachner M. Numerical simulations of unsteady multi-phase flows in an aero-engine like combustor. ISABE-2011-1101, 2011.

[86] Di Domenico M, Gerlinger P, Noll B. Numerical simulations of confined, turbulent, lean, premixed flames using a detailed chemistry combustion model. Proceedings of ASME Turbo Expo 2011, June 6-10, 2011, Vancouver, Canada, ASME-GT2011-45520.

[87] Eckel G, Rachner M, Le Clercq P, Di Domenico M, Aigner M. Unsteady simulation of liquid jet atomization in cross-flow at gas turbine conditions, ILASS - Europe 2011, 24 ${ }^{\text {th }}$ European Conference on Liquid Atomization and Spray Systems, Estoril, Portugal, September 2011.

[88] Reichling G, Noll B, Aigner M. Development of a Projection-Based Method for the Numerical Calculation of Compressible Reactive Flows, $51^{\text {st }}$ AIAA Aerospace Sciences Meeting including the 
New Horizons Forum and Aerospace Exposition, 07 - 10 January 2013, Grapevine, Texas, AIAA 2013-1003.

[89] Ivanova L, Noll B, Aigner M. A Numerical Study on the Turbulent Schmidt Numbers in a Jet in Crossflow. Journal of Engineering for Gas Turbines and Power 2013; 135 / 011505-1.

[90] Di Domenico M, Le Clercq P, Rachner M. Numerical simulations of unsteady multi-phase flows in an aero-engine like combustor. ISABE-2011-1101, 2011.

[91] Hafner S, Rashidia A, Baldea G, Riedel U. A detailed chemical kinetic model of high-temperature ethylene glycol gasification. Combustion Theory and Modelling 2011; 15 (4): 517-35.

[92] Le Clercq P, Bellan J. Direct numerical simulation of a transitional mixing layer laden with multicomponent-fuel evaporating drops using continuous thermodynamics. Phys. Fluids 2004; 16 (6): 1884-1907.

[93] Wilcox D.C. Turbulence modeling for CFD. DCW Industries, La Canada, California, 1993.

[94] Launder BE, Spalding DB. The Numerical Computation of Turbulent Flows. Computer Methods in Applied Mechanics and Engineering 1974; 3: 269-89.

[95] Jones WP, Lindestedt RP. Global reaction schemes for hydrocarbon combustion. Combust. Flame 1988; 73: 233-49.

[96] Westbrook CK, Dryer FL. Simplified reaction mechanisms for the oxidation of hydrocarbon fuels in flames. Combustion Science and Technology 1981; 27: 31-43.

[97] Magnussen BF. On the Structure of Turbulence and a Generalized Eddy Dissipation Concept for Chemical Reaction in Turbulent Flow. Nineteeth AIAA Meeting, St. Louis1981.

[98] Breussin F, Lallemant N and Weber R. Computing of oxy-natural gas flames using both a global combustion scheme and a chemical equilibrium procedure. Combustion Science and Technology, 2000;160, 369-397.

[99] Gran IR, Magnussen BF. A numerical study of a bluff-body stabilized diffusion flame. Part 2. Influence of combustion modeling and finite-rate chemistry. Combustion Science and Technology 1996; 119 (1-6) 191-217. 